Article

\title{
The Coordination and Luminescence of the Eu(III) Complexes with the Polymers (PMMA, PVP)
}

\author{
Weican Zhao ${ }^{1}$, Haifeng Shao ${ }^{1}$, Guang Yu ${ }^{1}$, Yanjun Hou ${ }^{1, *(1)}$ and Shuhong Wang ${ }^{2, *}$ \\ 1 School of Chemistry and Materials Science, Heilongjiang University, Harbin 150086, China; \\ 2151165@s.hlju.edu.cn (W.Z.); 2141100@s.hlju.edu.cn (H.S.); 2141097@s.hlju.edu.cn (G.Y.) \\ 2 Key Laboratory of Functional Inorganic Material Chemistry, Heilongjiang University, Harbin 150086, China \\ * Correspondence: houyj@hlju.edu.cn (Y.H.); wangshuhong@hlju.edu.cn (S.W.)
}

Received: 21 March 2018; Accepted: 4 May 2018; Published: 7 May 2018

check for updates

\begin{abstract}
The rare earth complexes and the polymers can be made into composite nanofibers through electrospinning. The fluorescence intensity of these fiber composites is much higher than that of the rare earth complexes. By changing the mixed proportion of polymethyl methacrylate (PMMA) and complexes, nanofiber materials were prepared. Then, by measuring their fluorescence intensity, it is found that the carbonyl bond of PMMA may have coordinated with the rare earth ions and enhanced the luminescence intensity of them. Then, a series of experiments were designed to study their coordination and luminescence mechanism. The coordination mechanism of the polymers with carbonyl groups and the rare earth complexes was explained by $\mathrm{Eu}(\mathrm{TFT})_{3}(\mathrm{TPPO}), \mathrm{Eu}(\mathrm{TFT})_{3}(\mathrm{TPPO})_{2}, \mathrm{Eu}(\mathrm{PFP})_{3}(\mathrm{TPPO}), \mathrm{Eu}(\mathrm{PFP})_{3}(\mathrm{TPPO})_{2}$, and polyvinyl pyrrolidone (PVP) dissolved in chloroform solution, where TFT means 2-(2,2,2-trifluoroethyl)-1-tetralone, PFP means 2-(2,2,3,3,3-Pentafluoropro-panoyl)-3,4-dihydronaphthalen-1(2H)-one and TPPO means phosphine oxide. The coordination of PVP and the rare earth complexes in solution was studied, and it was found that the fluorine atoms of the ligand had a significant impact on the aggregation-induced effect of the composites. The electron transitioned in the polymers and the complexes were enhanced greatly by the coordination. The colors of emission light could be adjusted by the coordination of the polymers and the rare earth complexes.
\end{abstract}

Keywords: complexes; luminescent; PMMA; composite nanofibers

\section{Introduction}

Lanthanide ions are widely used in the field of optical and magnetic researches on the basis of their peculiar luminescent and magnetic properties [1-6]. However, Ln(III) ions are unable to show a high luminous emission under direct excitation because the $\mathrm{f}-\mathrm{f}$ transitions of lanthanide ions are spin-forbidden. Many scientists find that the auxiliary ligands can play an important role in increasing the intensity of a luminous emission and inhibiting the quenching of fluorescence by an intramolecular energy transfer process from ancillary ligands to the central metal ion-the so-called "synergistic effect" [7]. The design of lanthanide coordination compounds has attracted particular attention in order to improve the luminescent properties of lanthanide ions.

In recent years, people with knowledge of the rare earth complexes attempted to take advantage of the polymers, which can be used as ligands to synthesize a series of macromolecular complexes. These macromolecular complexes have many unique properties [8-13]. Some polymers with carbonyl groups have been mixed with the rare earth complexes to be made into nanospinning materials. The fluorescence properties of nanospinning materials were studied, and their properties have been improved greatly $[14,15]$. However, the in-depth studies of their mechanism have not been reported. 
We all know that the molecular electron transitions of macromolecular polymers are different to those of the rare earth complexes $[16,17]$.

In our previous study, 2-(2,2,2-trifluoroethyl)-1-tetralone (TFT) and 2-(2,2,3,3,3-Pentafluoropropanoyl)-3,4-dihydronaphthalen-1(2H)-one (PFP) were used to synthesize firm coordination compounds with $\mathrm{Eu}^{3+}$ ions in order to enhance the luminescence intensity due to the effect of their $\pi-\pi^{*}$ transition [18-23]. In this paper, we further synthesized two ligands and six complexes. The coordination and luminescence mechanism of the complexes and the polymers were studied in different ways. The $\mathrm{Eu}(\mathrm{TFT})_{3}$ phen/PMMA and $\mathrm{Eu}(\mathrm{TFT})_{3}$ bpy /PMMA nanofibers were prepared by electrospinning technology, and the influence of $\mathrm{Eu}(\mathrm{III})$ complexes on both the morphology and the luminescence of composite nanofibers was researched. The synergistic luminescence mechanism of the complexes and the polymers was studied by the combination of some selected complexes with PVP. The polymers have a very strong characteristic emission. The rare earth complexes [24-30] and the polymers (carbonyl groups) can form unstable coordination, thus changing the fluorescence properties of the Eu(III) complexes [31-34]. Usually, the emitting colors from the electron transitions in the polymer molecules are blue, while the Eu(III) complexes emit red light. The emitting colors can be adjusted by the coordination of the polymers and the rare earth complexes.

\section{Synthesis and Characterization}

2.1. Synthesis of 2-(2,2,2-trifluoroethyl)-1-tetralone (TFT) and 2-(2,2,3,3,3-pentafluoropropanoyl)-3,4dihydronaphthalen-1(2H)-one (PFP)

1-tetralone $(5.00 \mathrm{mmol})$ in THF $(10 \mathrm{~mL})$ was added to a THF solution $(50 \mathrm{~mL})$ of ethyl trifluoroacetate (ethyl pentafluoro-propionate) $(10.00 \mathrm{mmol})$. The mixture was stirred for $1 \mathrm{~h}$. Later, $\mathrm{NaH}(7.5 \mathrm{mmol})$ solids were added with vigorous stirring, and the combined solution was stirred at $25^{\circ} \mathrm{C}$ for $24 \mathrm{~h}$ in an inert atmosphere. Then, a dilute hydrochloric acid solution $\left(0.5 \mathrm{~mol} \cdot \mathrm{L}^{-1}\right)$ was added to the solution to make the solution have a $\mathrm{pH}$. The mixed solution was extracted twice by dichloromethane. The organic layer was separated from the aqueous layer and dried overnight with anhydrous $\mathrm{Na}_{2} \mathrm{SO}_{4}$. After the solvent was removed by reduced pressure distillation, an oily solid was obtained. The solid product was isolated by column chromatography using hexane as an eluent (Scheme 1).

TFT: Yellow crystal. Yield: $81 \%$. m.p. $50.2-50.8^{\circ} \mathrm{C} .{ }^{1} \mathrm{H}$ NMR $\left(400 \mathrm{MHz}, \mathrm{CDCl}_{3}\right) \delta 15.66(\mathrm{~s}, 1 \mathrm{H})$, $7.99(\mathrm{~d}, J=7.8 \mathrm{~Hz}, 1 \mathrm{H}), 7.50(\mathrm{td}, J=7.5,1.4 \mathrm{~Hz}, 1 \mathrm{H}), 7.37(\mathrm{t}, J=7.4 \mathrm{~Hz}, 1 \mathrm{H}), 7.28-7.25(\mathrm{~m}, 1 \mathrm{H}), 3.49(\mathrm{~s}$, $1 \mathrm{H}), 2.94-2.87(\mathrm{~m}, 1 \mathrm{H}), 2.77(\mathrm{t}, J=6.8 \mathrm{~Hz}, 1 \mathrm{H}) \mathrm{IR}(\mathrm{KBr})$ vmax: $2947 \mathrm{~cm}^{-1}\left(\mathrm{~s}, v_{\mathrm{O}-\mathrm{H}}\right), 1600 \mathrm{~cm}^{-1}\left(\mathrm{~s}, v_{\mathrm{C}=\mathrm{O}}\right)$, $1303 \mathrm{~cm}^{-1}(\mathrm{~s}), 1246 \mathrm{~cm}^{-1}(\mathrm{~s}), 1139 \mathrm{~cm}^{-1}\left(\mathrm{~s}, v_{\mathrm{C}-\mathrm{F}}\right), 753 \mathrm{~cm}^{-1}\left(\mathrm{~m}, v_{\mathrm{CF} 3}\right)$.

PFP: Yellow solid. Yield: 79\%. m.p. 57.4-57.9 ${ }^{\circ} \mathrm{C} .{ }^{1} \mathrm{H}$ NMR $\left(400 \mathrm{MHz}, \mathrm{CDCl}_{3}\right) \delta 16.18(\mathrm{~s}, 1 \mathrm{H}), 8.01$ $(\mathrm{d}, J=8.3 \mathrm{~Hz}, 1 \mathrm{H}), 7.52(\mathrm{t}, J=7.5,1 \mathrm{H}), 7.38(\mathrm{t}, J=7.5 \mathrm{~Hz}, 1 \mathrm{H}), 7.27(\mathrm{~d}, J=6.1 \mathrm{~Hz}, 1 \mathrm{H}), 3.49(\mathrm{~s}, 1 \mathrm{H}), 2.90$ $(\mathrm{dd}, J=8.7,5.4 \mathrm{~Hz}, 2 \mathrm{H}), 2.84-2.78(\mathrm{~m}, 2 \mathrm{H})$. IR (KBr) vmax: $2924 \mathrm{~cm}^{-1}\left(\mathrm{~s}, v_{\mathrm{O}-\mathrm{H}}\right), 1597 \mathrm{~cm}^{-1}\left(\mathrm{~s}, v_{\mathrm{C}=\mathrm{O}}\right)$, $1324 \mathrm{~cm}^{-1}(\mathrm{~s}), 1222 \mathrm{~cm}^{-1}(\mathrm{~s}), 1158 \mathrm{~cm}^{-1}\left(\mathrm{~s}, v_{\mathrm{C}-\mathrm{F}}\right), 742 \mathrm{~cm}^{-1}\left(\mathrm{~m}, v_{\mathrm{CF} 3}\right)$.

The ${ }^{1} \mathrm{H}$ NMR spectra of TFT and PFP are shown in Appendix A (Figures A1 and A2).

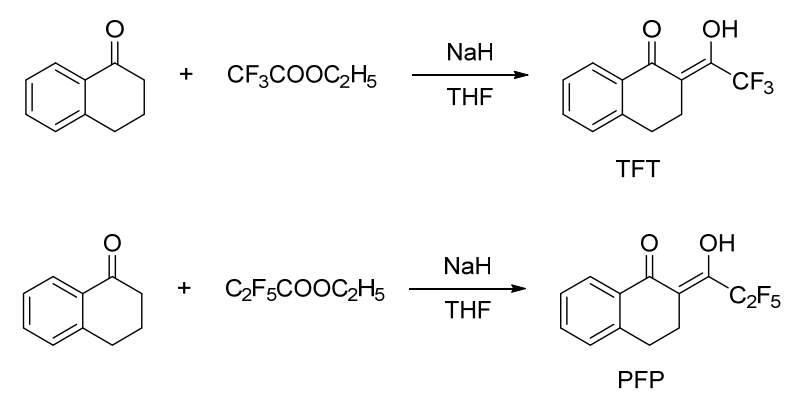

Scheme 1. Structures of compounds 2-(2,2,2-trifluoroethyl)-1-tetralone (TFT) and 2-(2,2,3,3,3Pentafluoropro-panoyl)-3,4-dihydronaphthalen-1(2H)-one (PFP). 


\subsection{Syntheses of Complexes 1-6}

Mixed TFT (PFP) $(4.12 \mathrm{mmol})$ and $\mathrm{NaOH}(4.12 \mathrm{mmol})$ in $\mathrm{CH}_{3} \mathrm{OH}(20 \mathrm{~mL})$ was stirred for $0.5 \mathrm{~h}$. Another methanol solution of $\mathrm{EuCl}_{3} \cdot 6 \mathrm{H}_{2} \mathrm{O}(1.38 \mathrm{mmol})$ was added dropwise under stirring. Then, the substances 1,10-o-Phenanthroline (Phen) or 2,2-Bispyridine (Bpy), phosphine oxide (TPPO), and TPPO $(2.76 \mathrm{mmol})(1.38 \mathrm{mmol})$ were added and stirred for $12 \mathrm{~h}$ at $25^{\circ} \mathrm{C}$ (Schemes 2 and 3). The products were obtained by reduced pressure distillation and washed with hexane, then recrystallized with the dichloromethane-hexane (Schemes 2-4).

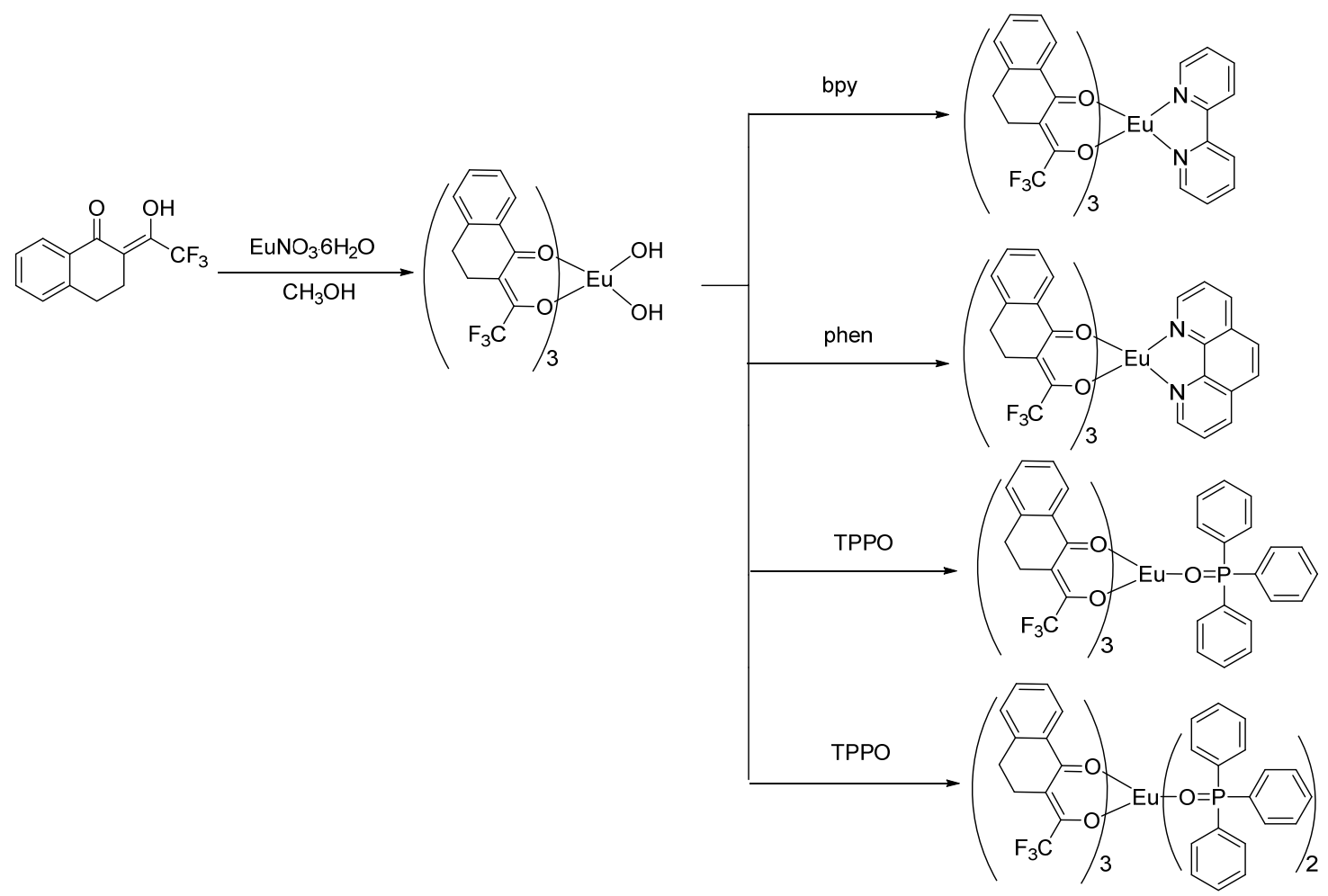

Scheme 2. Syntheses of complexes 1-4.

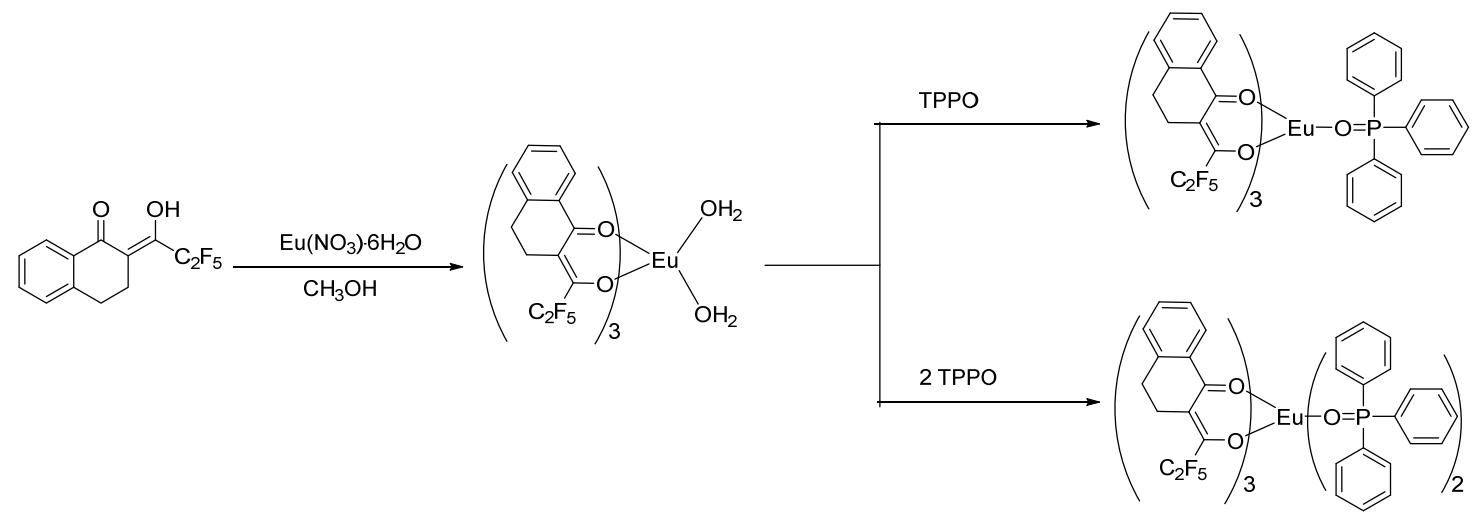

Scheme 3. Syntheses of complexes 5 and $\mathbf{6}$.

$\mathrm{Eu}(\mathrm{TFT})_{3}(\mathrm{bpy})(\mathbf{1})$ : Yield: $82 \%$ Anal. (\%) Calcd for $\mathrm{C}_{46} \mathrm{H}_{32} \mathrm{EuN}_{2} \mathrm{O}_{6} \mathrm{~F}_{9}\left(\mathrm{M}_{\mathrm{r}}=1031\right)$ : C 53.54, H 3.10; Found: C 53.43, H 3.12. IR data $\left(\mathrm{KBr}\right.$ pellet, $\left.\mathrm{cm}^{-1}\right): 1596 \mathrm{~cm}^{-1}\left(\mathrm{~s}, v_{\mathrm{C}=\mathrm{O}}\right), 1302 \mathrm{~cm}^{-1}(\mathrm{~s}), 1231 \mathrm{~cm}^{-1}(\mathrm{~s})$, $1123 \mathrm{~cm}^{-1}\left(\mathrm{~s}, v_{\mathrm{C}-\mathrm{F}}\right), 754 \mathrm{~cm}^{-1}\left(\mathrm{~m}, v_{\mathrm{CF} 3}\right)$. 
$\mathrm{Eu}(\mathrm{TFT})_{3}$ (phen)(2): Yield: 87\% Anal. (\%) Calcd for $\mathrm{C}_{48} \mathrm{H}_{32} \mathrm{EuN}_{2} \mathrm{O}_{6} \mathrm{~F}_{9}\left(M_{\mathrm{r}}=1055\right)$ : C 54.60, H 3.05; Found: C 54.62, H 3.08. IR data (KBr pellet, $\left.\mathrm{cm}^{-1}\right): 1596 \mathrm{~cm}^{-1}\left(\mathrm{~s}, v_{\mathrm{C}=\mathrm{O}}\right), 1303 \mathrm{~cm}^{-1}$ (s), $1233 \mathrm{~cm}^{-1}$ (s), $1126 \mathrm{~cm}^{-1}\left(\mathrm{~s}, v_{\mathrm{C}-\mathrm{F}}\right), 755 \mathrm{~cm}^{-1}\left(\mathrm{~m}, \mathrm{v}_{\mathrm{CF} 3}\right)$.

$\mathrm{Eu}(\mathrm{TFT})_{3}(\mathrm{TPPO})(3)$ : Yield: $79 \%$ Anal. (\%) Calcd for $\mathrm{C}_{54} \mathrm{H}_{39} \mathrm{EuPO}_{7} \mathrm{~F}_{9}\left(M_{\mathrm{r}}=1153\right)$ : C 56.20, H 3.38; Found: C 56.18, H 3.35. IR data (KBr pellet, $\left.\mathrm{cm}^{-1}\right): 1595 \mathrm{~cm}^{-1}\left(\mathrm{~s}, v_{\mathrm{C}=\mathrm{O}}\right), 1302 \mathrm{~cm}^{-1}$ (s), $1234 \mathrm{~cm}^{-1}$ (s), $1120 \mathrm{~cm}^{-1}\left(\mathrm{~s}, v_{\mathrm{C}-\mathrm{F}}\right), 755 \mathrm{~cm}^{-1}\left(\mathrm{~m}, v_{\mathrm{CF} 3}\right)$.

$\mathrm{Eu}(\mathrm{TFT})_{3}(\mathrm{TPPO})_{2}(4)$ : Yield: $82 \%$ Anal. (\%) Calcd for $\mathrm{C}_{72} \mathrm{H}_{54} \mathrm{EuP}_{2} \mathrm{O}_{8} \mathrm{~F}_{9}\left(M_{\mathrm{r}}=1431\right): \mathrm{C} 60.38, \mathrm{H} 3.77$; Found: C 60.35, H 3.79. IR data $\left(\mathrm{KBr}\right.$ pellet, $\left.\mathrm{cm}^{-1}\right): 1597 \mathrm{~cm}^{-1}\left(\mathrm{~s}, \mathrm{v}_{\mathrm{C}=\mathrm{O}}\right), 1303 \mathrm{~cm}^{-1}(\mathrm{~s}), 1232 \mathrm{~cm}^{-1}(\mathrm{~s})$, $1121 \mathrm{~cm}^{-1}\left(\mathrm{~s}, v_{\mathrm{C}-\mathrm{F}}\right), 754 \mathrm{~cm}^{-1}\left(\mathrm{~m}, v_{\mathrm{CF} 3}\right)$.

$\mathrm{Eu}(\mathrm{PFP})_{3}(\mathrm{TPPO})(5)$ : Yield: $82 \%$ Anal. (\%) Calcd for $\mathrm{C}_{57} \mathrm{H}_{39} \mathrm{EuPO}_{7} \mathrm{~F}_{15}\left(M_{\mathrm{r}}=1272\right)$ : C 53.77, H 3.07; Found: C 53.74, H 3.12. IR data (KBr pellet, $\left.\mathrm{cm}^{-1}\right): 1595 \mathrm{~cm}^{-1}\left(\mathrm{~s}, v_{\mathrm{C}=\mathrm{O}}\right), 1291 \mathrm{~cm}^{-1}$ (s), $1221 \mathrm{~cm}^{-1}$ (s), $1124 \mathrm{~cm}^{-1}\left(\mathrm{~s}, v_{\mathrm{C}-\mathrm{F}}\right), 752 \mathrm{~cm}^{-1}\left(\mathrm{~m}, v_{\mathrm{CF} 3}\right)$.

$\mathrm{Eu}(\mathrm{PFP})_{3}(\mathrm{TPPO})_{2}(6)$ : Yield: $83 \%$ Anal. (\%) Calcd for $\mathrm{C}_{75} \mathrm{H}_{54} \mathrm{EuP}_{2} \mathrm{O}_{8} \mathrm{~F}_{15}\left(M_{\mathrm{r}}=1581\right): \mathrm{C} 56.93$, H 3.42; Found: C 56.89, H 3.37. IR data $\left(\mathrm{KBr}\right.$ pellet, $\left.\mathrm{cm}^{-1}\right): 1597 \mathrm{~cm}^{-1}\left(\mathrm{~s}, v_{\mathrm{C}=\mathrm{O}}\right), 1291 \mathrm{~cm}^{-1}(\mathrm{~s})$, $1227 \mathrm{~cm}^{-1}(\mathrm{~s}), 1122 \mathrm{~cm}^{-1}\left(\mathrm{~s}, v_{\mathrm{C}-\mathrm{F}}\right), 751 \mathrm{~cm}^{-1}\left(\mathrm{~m}, v_{\mathrm{CF} 3}\right)$.

The FTIR spectra of TFT, PFP, complexes 1-6 are shown in Appendix B (Figures A3-A12). FTIR spectra of TFT, complexes $\mathbf{2 - 4}$ and Eu(TFT) $)_{3}$ (phen)/polymethyl methacrylate (PMMA), which was synthesized in subsequent experiments, are shown in Figure 1 for comparison purposes.

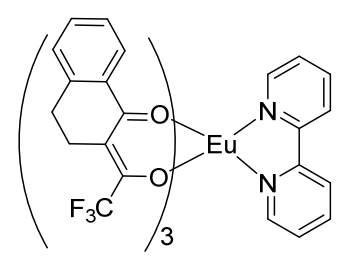

$\mathrm{Eu}(\mathrm{TFT})_{3}(\mathrm{bpy})(1)$

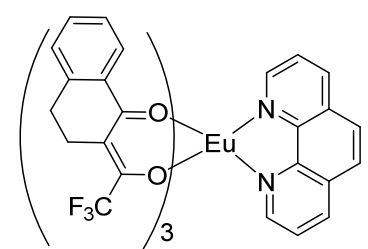

$\mathrm{Eu}(\mathrm{TFT})_{3}($ phen)(2)

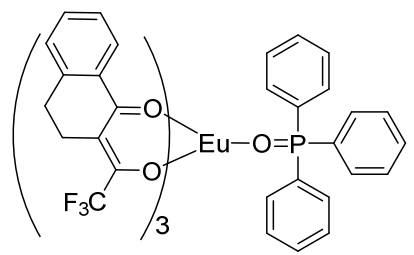

$\mathrm{Eu}(\mathrm{TFT})_{3}(\mathrm{TPPO})(3)$

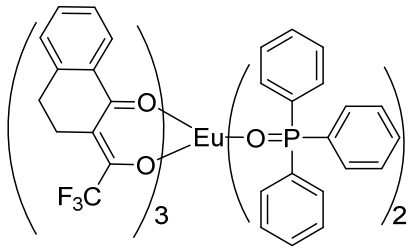

$\mathrm{Eu}(\mathrm{TFT})_{3}(\mathrm{TPPO})_{2}(4)$

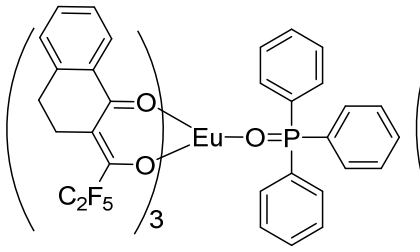

$\mathrm{Eu}(\mathrm{PFP})_{3}(\mathrm{TPPO})(5)$

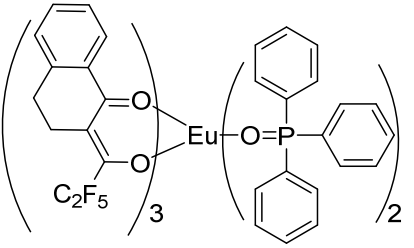

$\mathrm{Eu}(\mathrm{PFP})_{3}(\mathrm{TPPO})_{2}(\mathbf{6})$

Scheme 4. Structures of complexes 1-6.

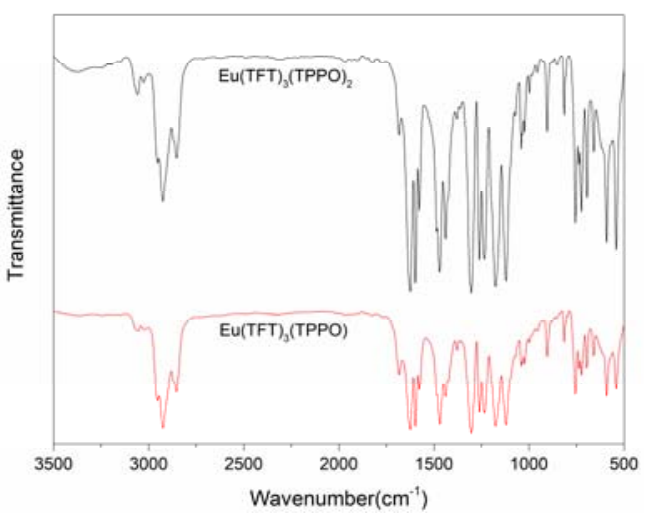

(a)

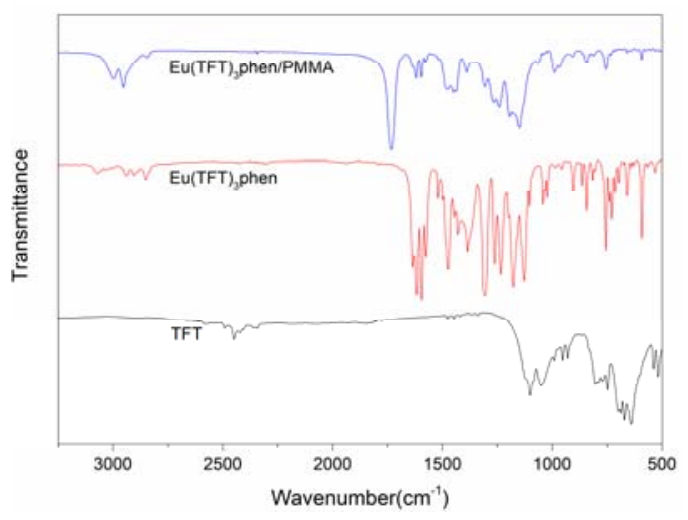

(b)

Figure 1. FTIR spectra of TFT, Eu(TFT) 3 (phen)/polymethyl methacrylate (PMMA) and complexes 2-4. 


\subsection{Molecular Structures of the Complexes $\mathbf{1}$ and $\mathbf{2}$}

The molecular structures of the complexes $\mathbf{1}$ and $\mathbf{2}$ were revealed by single crystal X-ray studies, which crystallize in the monoclinic crystal system with space groups of $P 2_{1} / n$ and $P 2_{1} / c$, respectively. The asymmetric unit of complex $\mathbf{1}$ is composed of one $\mathrm{Eu}^{3+}$ ion, three deprotonated ligands, and one auxiliary ligand (phen, bpy). Each $\mathrm{Eu}^{3+}$ ion center adopts a distorted hexahedron geometry, coordinated by six $\mathrm{O}$ atoms from three carbonyl groups $(\mathrm{O} 1, \mathrm{O} 3, \mathrm{O} 5)$, three hydroxy groups $(\mathrm{O} 2, \mathrm{O} 4, \mathrm{O} 6)$ of three ligands, and two $\mathrm{N}$ atoms (N1, N2) from one auxiliary ligand (Figure 2a,b). The average bond lengths of the Eu-O and Eu-N for complex 1 are $2.347 \AA$ and $2.588 \AA$, respectively. The average bond lengths of the Eu-O and Eu-N for complex 2 are $2.357 \AA$ and $2.583 \AA$ (Appendix D, Tables A1 and A2), respectively. The average length of the $\mathrm{Eu}-\mathrm{N}$ bond with the nitrogen atoms from the auxiliary ligand is substantially longer, indicating a weak interaction. In other words, the TFT ligand is more stable when bound to the central metal ion, which is due to the strong interaction between the $\mathrm{Eu}^{3+}$ ion and the oxygen atoms. In comparison with complex 1, complex 2 introduces the solvent n-hexane.

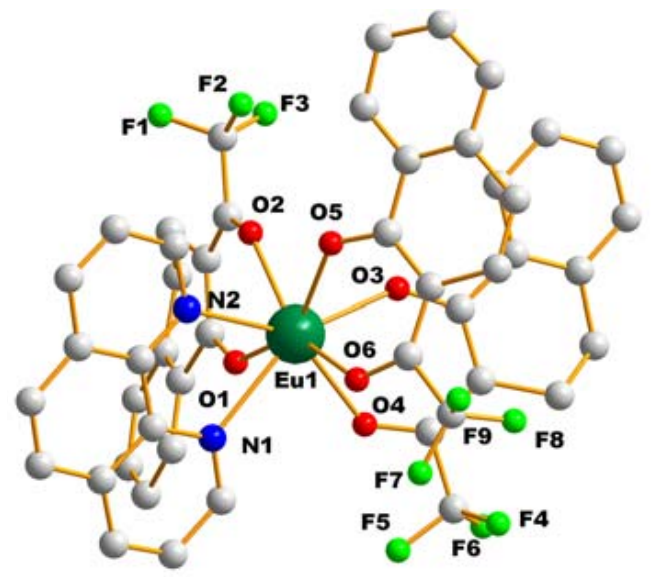

(a)

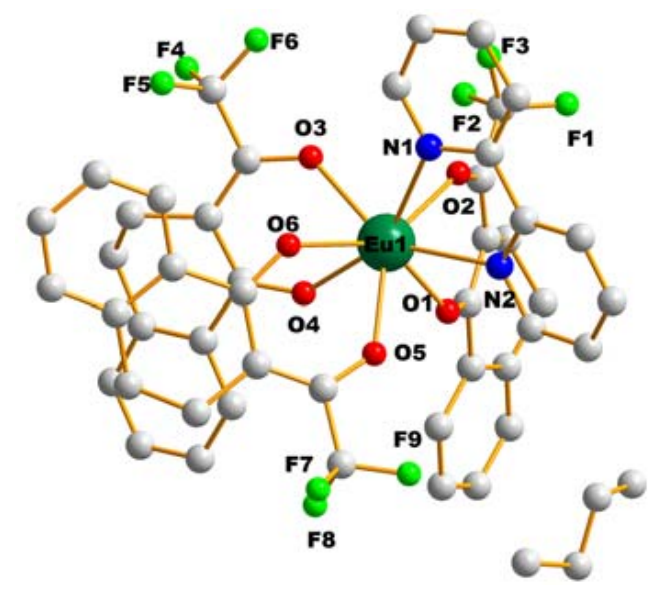

(b)

Figure 2. Molecular structure for $\mathrm{Eu}(\mathrm{TFT})_{3}$ (phen) $(\mathbf{a})$ and $\mathrm{Eu}(\mathrm{TFT})_{3}(\mathrm{bpy}) \cdot 1 / 2 \mathrm{Hex}(\mathbf{b})$.

\subsection{Morphology of Composite Nanofibers and Dispersion of Eu/PMMA.}

The SEM images of typical electrospun nanofibers demonstrated that the nanofibers of $\mathrm{Eu}(\mathrm{TFT})_{3}$ phen/PMMA, Eu(TFT) ${ }_{3}$ bpy/PMMA were successfully prepared (Figure 3a-d), and both nanofibers appeared to be distinctly separated and randomly interspersed. The surface of the composite nanofibers was smooth without identifiable particles, suggesting that complex 1 (or 2) might be uniformly dispersed into the nanofibers. Figure $4 a, b$ disposed the fluorescence microscope images of $\mathrm{Eu}(\mathrm{TFT})_{3}$ phen/PMMA and Eu(TFT) $)_{3}$ bpy/PMMA composite nanofibers, respectively. The carbonyl bond of PMMA and the rare earth ions could have produced coordination bonds. Their composite materials were used as electron transport carriers, and they could be fabricated as electrospinning fibers. More importantly, the aggregation of the Eu/PMMA composite led to the formation of nanoparticles in the composite fibers during the entire electrospinning process. 


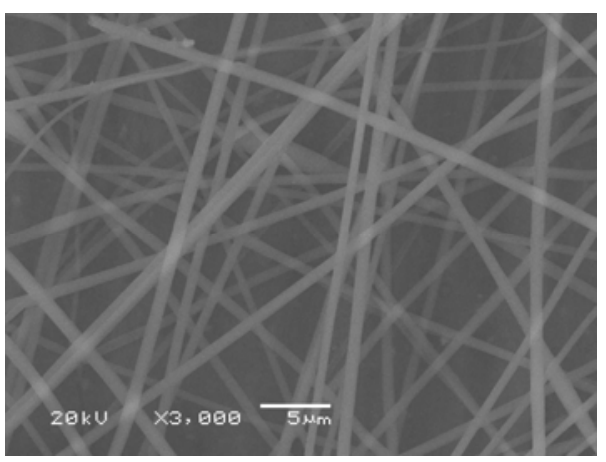

(a)

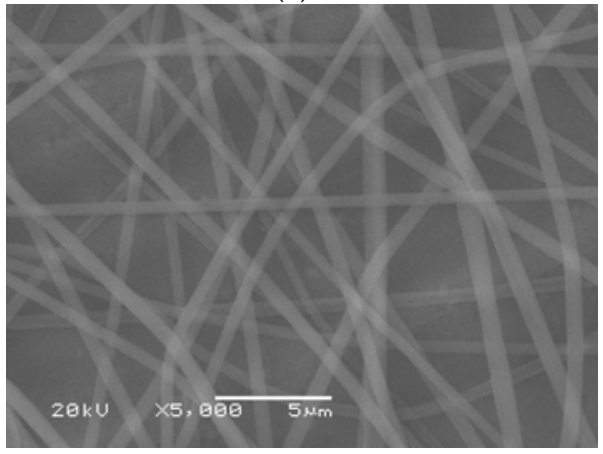

(c)

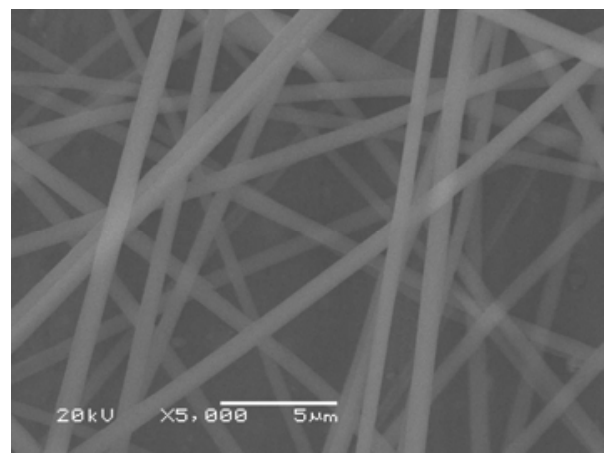

(b)

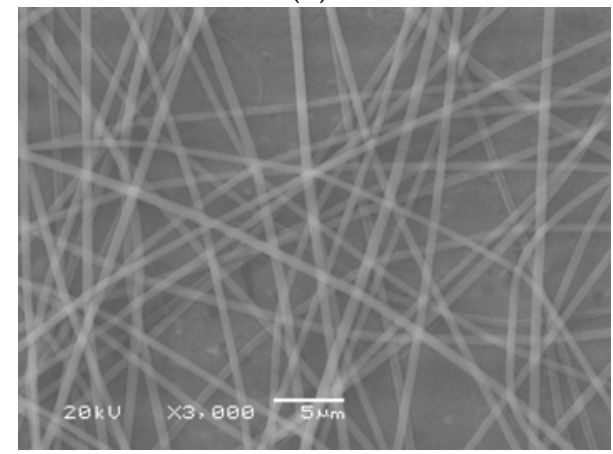

(d)

Figure 3. SEM images of the composite nanofibers of $\operatorname{Eu}(\mathrm{TFT})_{3}$ phen/PMMA $(\mathbf{a}, \mathbf{b})$, $\mathrm{Eu}(\mathrm{TFT})_{3}$ bpy /PMMA (c,d).

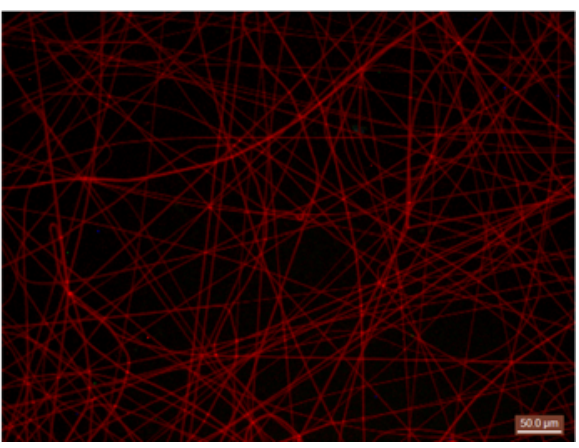

(a)

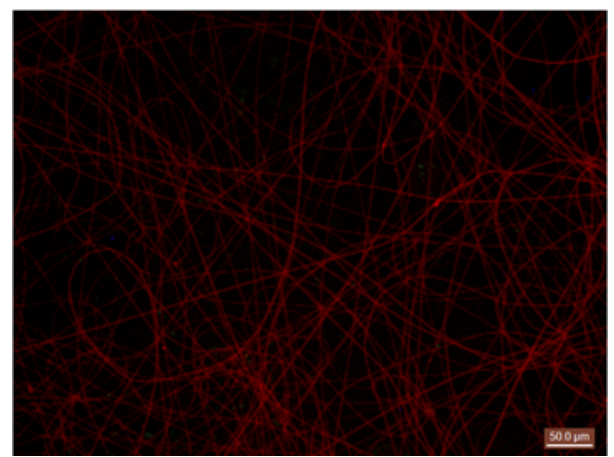

(b)

Figure 4. The fluorescence microscope images of Eu(TFT) ${ }_{3}$ phen/PMMA (a) and Eu(TFT) $)_{3}$ bpy/PMMA (b) composite nanofibers.

\section{Results and Discussion}

\subsection{UV-Vis Spectral Analysis}

The ultraviolet absorption spectra of TFT and complexes $\mathbf{1}$ and $\mathbf{2}$ are shown in the $\mathrm{CH}_{3} \mathrm{CN}$ solution $\left(1 \times 10^{-5} \mathrm{~mol} \cdot \mathrm{L}^{-1}\right)$. According to the spectra (Figure 5), the absorption broad band appeared to be slightly blue-shift from $363 \mathrm{~nm}$ for the TFT to $362 \mathrm{~nm}$ for the Na(TFT) because of the transfer of the $\beta$-diketonate proton. In addition, the maximal absorption of Phen and Bpy was 263 and $272 \mathrm{~nm}$, respectively. This was due to the singlet-singlet $\pi-\pi^{*}$ absorption of the ancillary ligand. As for complexes 1 and 2, the two typical UV-Vis absorption peaks were 353 and 359 nm, respectively. They had high absorption intensities, which were blue-shifted compared to ligand TFT (363 nm), due 
to the influence of TFT complexed with the $\mathrm{Eu}^{3+}$ ion. In addition, the molar absorption coefficient values of complexes 1 and 2 were approximately $0.9 \times 10^{5} \mathrm{~L} \cdot \mathrm{mol}^{-1} \cdot \mathrm{cm}^{-1}$ around $350-360 \mathrm{~nm}$, which was three times higher than the ligand base on each of the complexes consisting of three ligands.

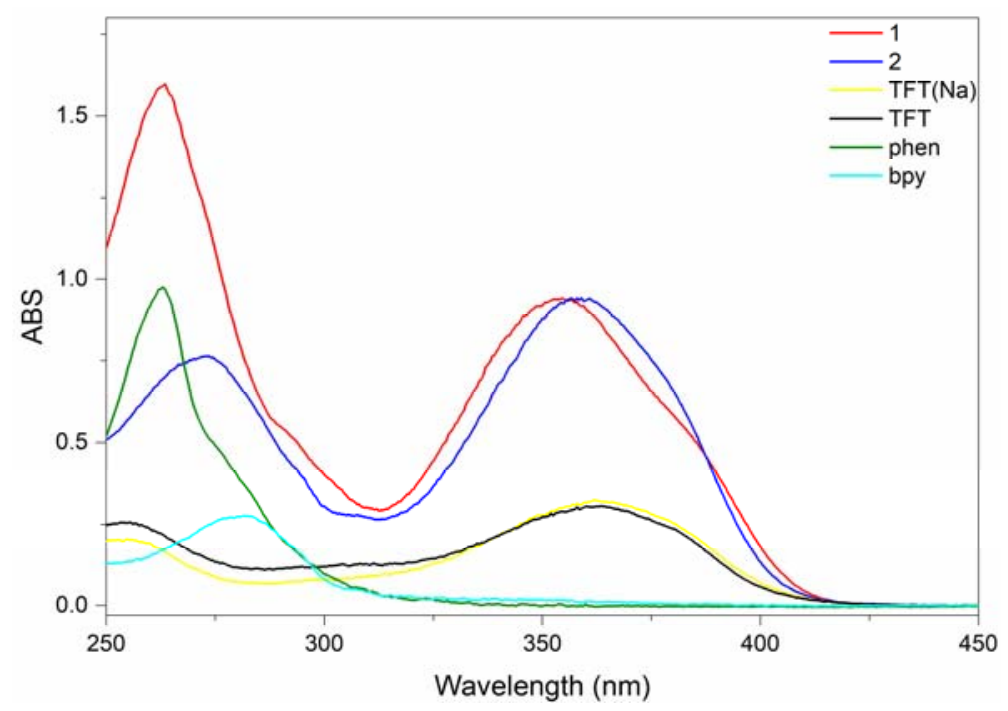

Figure 5. UV-Vis absorption spectra of complexes 1 and 2 and TFT, $\mathrm{Na}(\mathrm{TFT})$, phen, bpy in the $\mathrm{CH}_{3} \mathrm{CN}$ solution in the UV-Vis spectrum.

The calculated HOMO and LUMO levels of the ground state were -0.21 and $-0.30 \mathrm{eV}$, respectively, while the values for singlet excitation of complex 1 were -0.08 and $0.05 \mathrm{eV}$ (Table A3), respectively. Both the electronic distributions of HOMO localize at TFT, while those of LUMO localize at phen (Figure 6). The lowest excitation energy of complex 1 was $4.47 \mathrm{eV}$. The intraligand charge transfer, the metal-to-ligand charge transfer, and the metal center conversion are the major reasons for the absorption transitions. The calculation data corresponded with the phenomena that the absorption intensity of the complexes was approximately two times higher than that of the ligand.

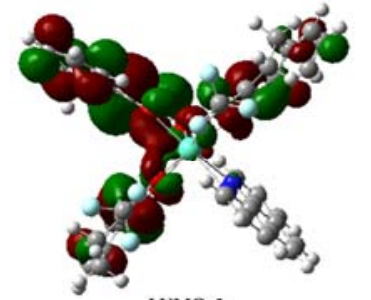

LUMO+3

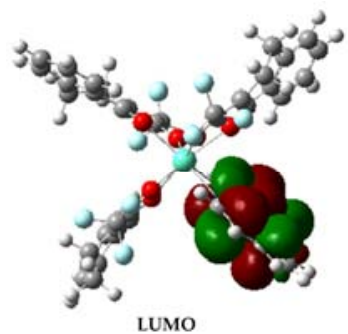

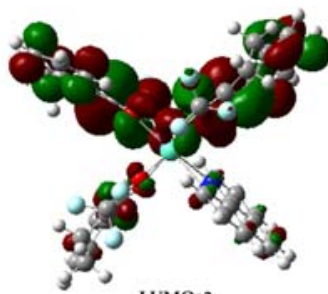

LUMO+2

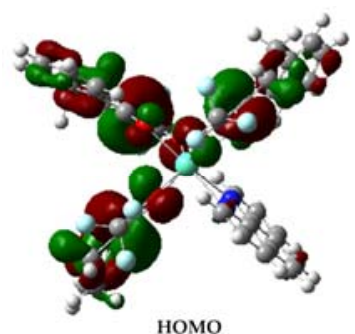

HOMO
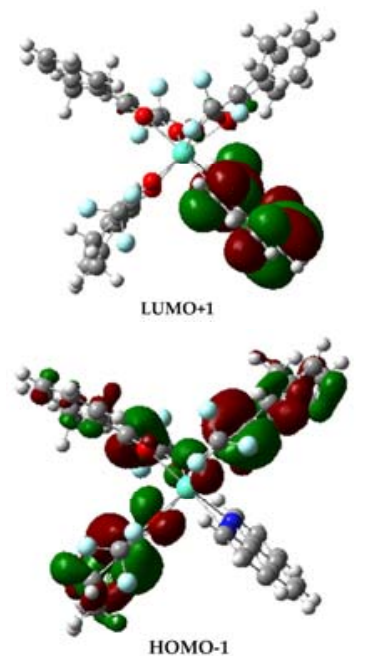

Figure 6. Spatial plots of the selected frontier molecular orbits of the excited states of complex 1.

\subsection{Thermal Stability Analysis}

The thermal stabilities of complexes 1 and $\mathbf{2}$ (Figure 7) were analyzed with thermogravimetric analysis (TGA) in a temperature range from 50 to $720^{\circ} \mathrm{C}$ at a rate of $10{ }^{\circ} \mathrm{C} \cdot \mathrm{min}^{-1}$ under a nitrogenous 
gas atmosphere. Within the temperature range of $250-650{ }^{\circ} \mathrm{C}$, the TGA curve of complex 1 showed that the weightlessness rate was $85.9 \%$, which corresponds to how the TFT and phen ligands (calcd $86.1 \%$ ) decomposed gradually. Within the temperature range of $190-210^{\circ} \mathrm{C}$, the TGA curve of complex 2 showed a weight loss of $4 \%$, corresponding to how the solvent $n$-hexane (calcd $4 \%$ ) evaporated gradually. In the temperature range of $250-650{ }^{\circ} \mathrm{C}$, a weight loss of $76.2 \%$ corresponded to how the TFT and bpy ligands (calcd 76.8\%) decomposed gradually. The final mass residues of complexes 1 and 2 were europium oxide.

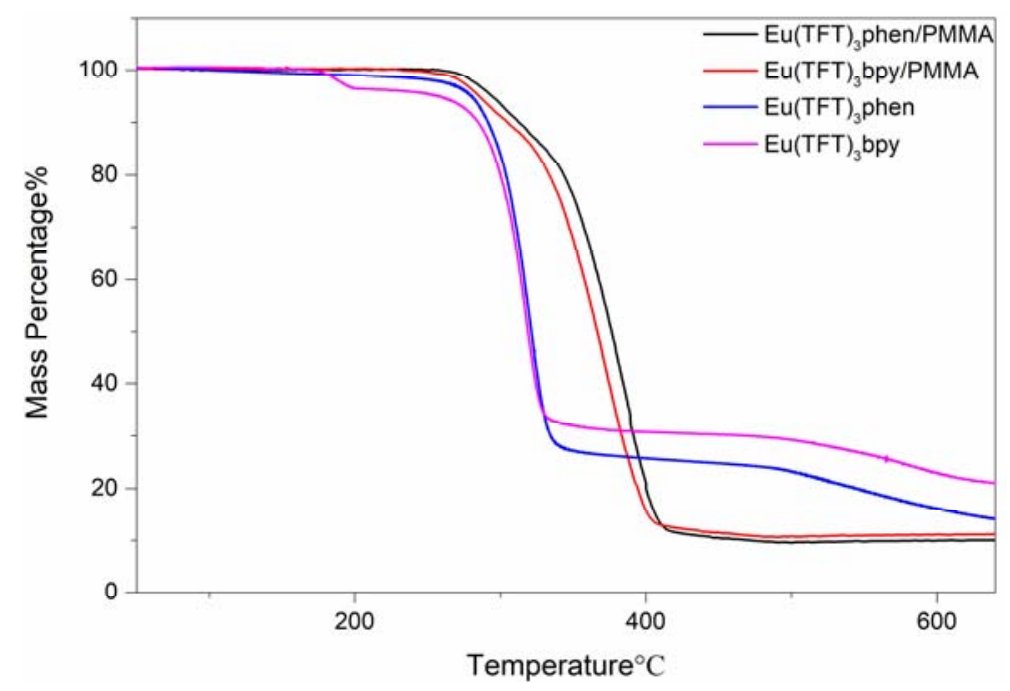

Figure 7. TGA curves of the complexes 1 and 2, Eu(TFT) $)_{3}$ phen/PMMA, and Eu(TFT) $)_{3}$ bpy/PMMA.

We take complex 1 as an example. The experimental results show that the initial decomposition temperature of the composite is approximately $268^{\circ} \mathrm{C}$. It is higher than the decomposition temperature of complex 1 by $18^{\circ} \mathrm{C}$. The Eu/PMMA composite nanofiber produces a thermal behavior in a wide temperature range from 268 to $410{ }^{\circ} \mathrm{C}$, which is $80^{\circ} \mathrm{C}$ higher than that of the undoped polymethyl methacrylate (PMMA) fiber. The result shows that when the PMMA is used as the polymer matrix, the rigid chain segment of the polymer has a limited effect on the vibration of the organic ligand and improves the relative independence of the doping molecule, such that the complex can remain stable in a good environment.

\subsection{The Photoluminescent Properties of Complexes}

The fluorescence spectra of TFT and complexes $\mathbf{1}$ and $\mathbf{2}$ are shown in Figure 8. The several characteristic narrow emission bands of the $\mathrm{Eu}^{3+}$ ion are formed upon excitation at 390-410 $\mathrm{nm}$ (Figure 8a), corresponding to the transitions from the metal-centered ${ }^{5} \mathrm{D}_{0}$ excited state to the ${ }^{7} \mathrm{~F}_{\mathrm{J}}$ ground state (Figure $8 b$ ), respectively. Among them, the ${ }^{5} \mathrm{D}_{0} \rightarrow{ }^{7} \mathrm{~F}_{\mathrm{J}}$ transition around $611 \mathrm{~nm}$ is the highest intensity emission, which belongs to an induced electric dipole transition, indicating that the $\mathrm{Eu}^{3+}$ ion is not situated in a location with inversion center symmetry.

The Eu(III) complexes have the strongest fluorescence intensity among the lanthanide series and emit red light at 605-700 nm. The blue light emission appeared at 450-480 nm. As can be seen in Figure $8 b$, the broad emission band of organic ligands $\left(\lambda_{\mathrm{em}}=468 \mathrm{~nm}\right)$ cannot be observed in field of complexes 1 and 2. Therefore, it is effective to transfer the absorbed energy to the emission level of the $\mathrm{Eu}^{3+}$ ion. Meanwhile, we discovered that the emission peak of complex $\mathbf{1}$ was stronger than complex 2; the main reason for this was the difference in the auxiliary ligand. The light absorption of the auxiliary ligand of complexes $\mathbf{1}$ and $\mathbf{2}$ was different. The phen ligand had a higher efficiency of light absorption and an energy in the triplet excited state that was higher than the lowest emitting level of the Eu(III). 


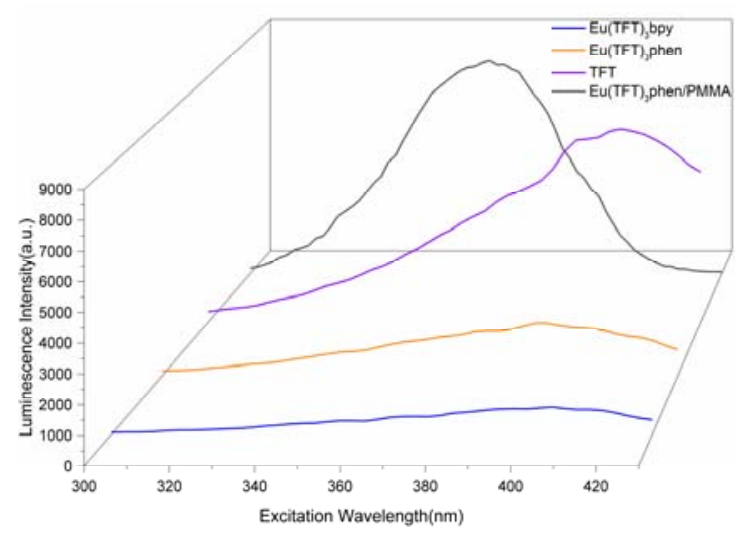

(a)

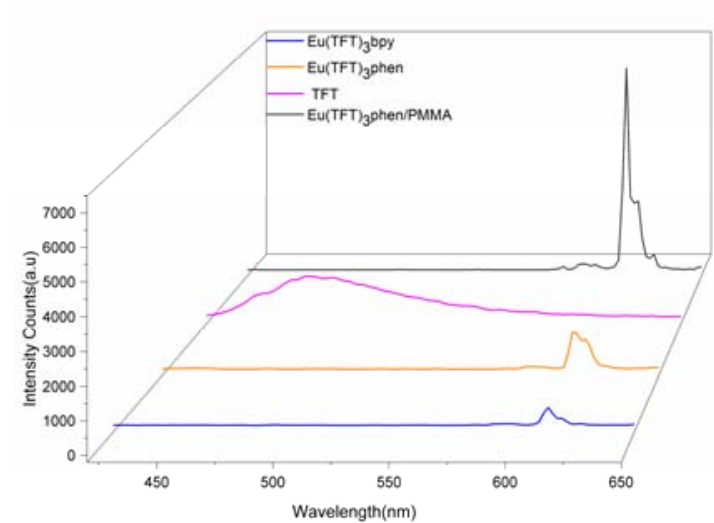

(b)

Figure 8. The excitation (a) and emission (b) spectra of complexes 1, 2, TFT, Eu(TFT) $)_{3}$ phen/PMMA $(12 \%)$ in the solid state.

\subsection{The Photoluminescent Properties of PMMA, PVP/Complexes Composites}

The emission spectra of the composite nanofibers with $\mathrm{Eu}(\mathrm{TFT})_{3}$ phen/PMMA and the emission spectra of complexes $\mathbf{1}$ and 2 and Eu/PVP composite fibers with a content of 12 wt \% are shown in Figure 9a,b. We found that the fluorescence intensity of the complexes in PMMA was significantly improved. With an increase in doping level, the fluorescence emission intensity increased gradually, then showed a decreasing trend after reaching a maximum strength with a $\mathrm{Eu}(\mathrm{TFT})_{3}$ phen content of $12 \mathrm{wt} \%$ during emission. The ${ }^{5} \mathrm{D}_{0} \rightarrow{ }^{7} \mathrm{~F}_{2}$ fluorescence emission peaks of $\mathrm{Eu} / \mathrm{PMMA}$ composite fibers were higher than that of the $\mathrm{Eu}^{3+}$ complexes. The emission intensity of $\mathrm{Eu}(\mathrm{TFT})_{3}$ phen/PMMA was clearly stronger than Eu(TFT) $)_{3}$ bpy/PMMA, which is consistent with the fluorescence microscope images.

The polymers have a strong isolation effect, and they are not easy to react with small molecular compounds. By changing the mixed proportion of PMMA and complexes and measuring their fluorescence intensity, it was found that PMMA's carbonyl bond may have coordinated with the rare earth ions to enhance the luminescence intensity of the rare earth ions (Scheme 5). In order to study the coordination and luminescence mechanism of the rare earth complexes and the polymers, we designed a series of experiments. Eu(TFT) $)_{3}(\mathrm{TPPO})(0.07 \mathrm{~g})$ and $\mathrm{Eu}(\mathrm{TFT})_{3}(\mathrm{TPPO})_{2}(0.07 \mathrm{~g})$ were dissolved in chloroform $(50 \mathrm{~mL})$, respectively. Then, polyvinyl pyrrolidone (PVP) was added to the solution to test their liquid fluorescence properties, and the liquid fluorescence spectra were obtained (Figure 10a,b). By analyzing the liquid fluorescence spectra, we found that the liquid fluorescence intensities of $\mathrm{Eu}(\mathrm{TFT})_{3}(\mathrm{TPPO})$ and $\mathrm{Eu}(\mathrm{TFT})_{3}(\mathrm{TPPO})_{2}$ were almost the same. This shows that the roles of two TPPO molecules and one TPPO molecule were almost identical. The fluorescence properties of the rare earth complexes depended on the electron-stretching transfer in the complexes. In the process of electron stretching in rare earth complexes, the difference in electronic tensile transmission between two TPPO molecules and one TPPO molecule was very small. However, when PVP was added, the liquid fluorescence curves changed significantly. The emission peak intensity was significantly improved at $612 \mathrm{~nm}$. At approximately $500 \mathrm{~nm}$, there was a strong launch peak, which was caused by PVP. PVP had an intramolecular electron transition. The carbonyl bond of PVP and the ligand coordinated, which could have enhanced the intramolecular transition of PVP and increased the aggregation-induction effect of molecules. The emission peaks of 500 and $612 \mathrm{~nm}$ exist simultaneously, which could have adjusted the luminescence color of the complexes (Figure 10a,b). When the mass fraction of $\mathrm{Eu}(\mathrm{TFT})_{3}$ (TPPO)/PVP was $23 \mathrm{wt} \%$, its liquid fluorescence intensity was at its highest (345 nm). When the mass fraction of $\mathrm{Eu}(\mathrm{TFT})_{3}(\mathrm{TPPO})_{2} / \mathrm{PVP}$ was $15 \mathrm{wt} \%$, its liquid fluorescence intensity was at its highest $(345 \mathrm{~nm})$. When the concentration was too high, they produced the aggregation-induced quenching, and the fluorescence intensity decreased. At the same time, the 
emission wavelengths of 500 and $612 \mathrm{~nm}$ were not quenched synchronously, indicating that the polymers were different from the fluorescence mechanism of the rare earth complexes. In theory, the rare earth ions and ligands could form twelve -coordination complexes, but because of space resistance, the trivalent rare earth ions and ligands could form stable complexes of eight-coordination, and the rare earth complexes of nine(ten)-coordination were not very stable.

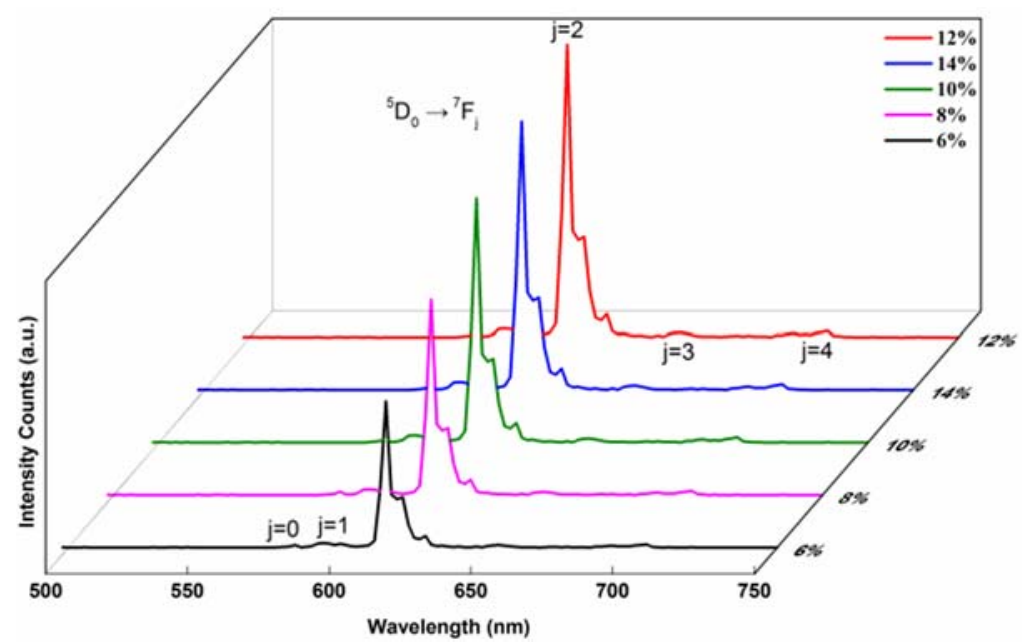

(a)

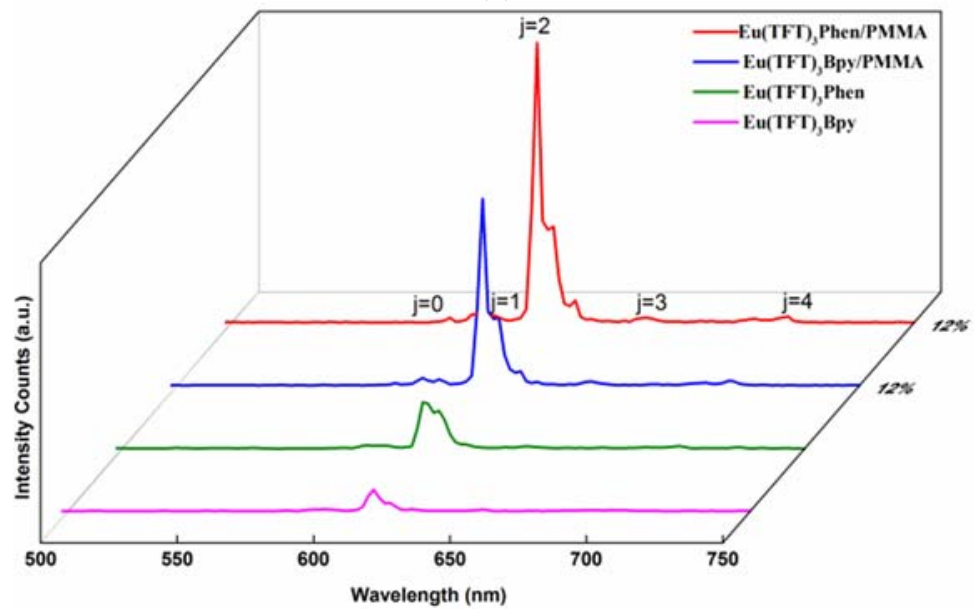

(b)

Figure 9. The emission spectra of the composite nanofibers Eu(TFT) ${ }_{3}$ phen/PMMA (a); The emission spectra of complexes 1, 2 and Eu/PVP composite fibers content of $12 \mathrm{wt} \%$ (b).

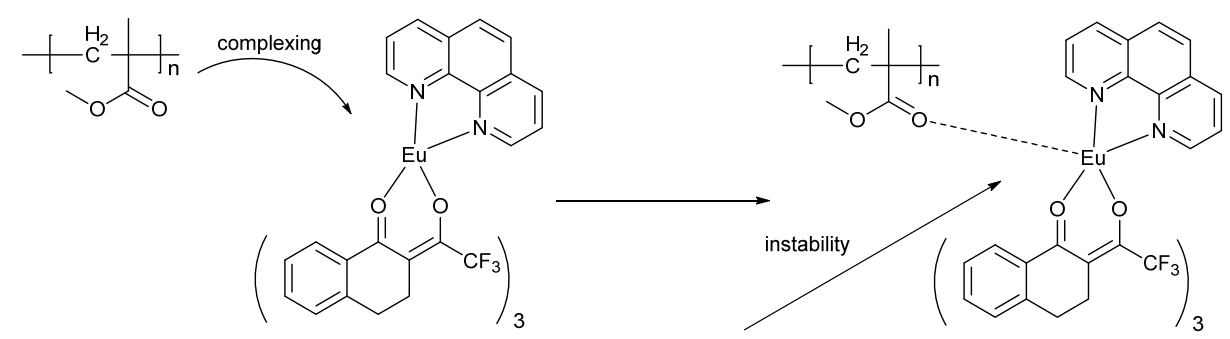

Scheme 5. Coordination mechanism of $\mathrm{Eu}(\mathrm{TFT})_{3}($ phen)/PMMA. 


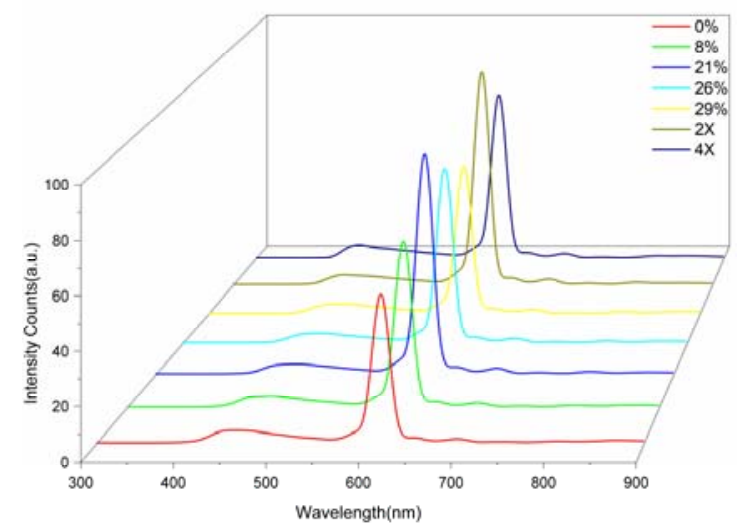

(a)

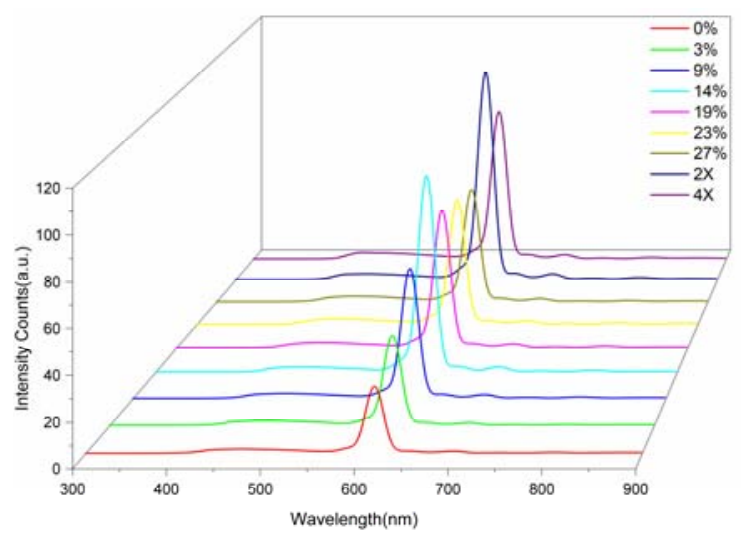

(b)

Figure 10. The liquid fluorescence curve spectrograms of complexes 3 (a) and 4 (b) in chloroform.

The fluorescence intensities of the rare earth complexes were increased in methanol, 1,2-dimethoxyethane, and acetonitrile due to their association with the solvent. The oxygen atoms (nitrogen atoms) of the solvent and the $\mathrm{Eu}^{3+}$ ions of the rare earth complexes could form coordination bonds, which enhanced the fluorescence properties of the Eu(III) complexes. However, the coordination bond was unstable. The Eu(III) complexes could be mixed with PMMA, PVP, and polyacrylonitrile (PAN) to make composite nanofibers. The fluorescence properties of the mixed Eu(III) complexes with these polymers were improved significantly because these polymers and the $\operatorname{Ln}(\mathrm{III})$ ions of complexes could form new complexes. The different types of auxiliary ligands were added and the fluorescence intensity of the complexes could be clearly improved.

Complex $3(0.07 \mathrm{~g})$ was added to $\mathrm{N}, \mathrm{N}$-dimethyl formamide (DMF) $(50 \mathrm{~mL})$. Then, PVP was added to the DMF solution. We found that the fluorescence intensity of the solution decreased slightly. The carbonyl bond of DMF could form a coordination bond with the $\mathrm{Eu}(\mathrm{III})$ ion of the rare earth complexes. However, the carbonyl bond of PVP, which is soluble in DMF, could not be coordinated with the complexes. There was no emission peak caused by PVP (Appendix C Figure A13). The emission peak near $500 \mathrm{~nm}$ was caused by the coordination of PVP and the rare earth complexes, which greatly enhanced the electron transition in polymer molecules. We found that the thermal stabilities of $\mathrm{Eu}(\mathrm{TFT})_{3}$ phen/PMMA and $\mathrm{Eu}(\mathrm{TFT})_{3}$ bpy/PMMA were improved by the analysis of heat loss. The experimental results showed that the oxygen atoms of PMMA and Eu(III) ions of complexes $\mathbf{1}$ and $\mathbf{2}$ formed new coordination bonds. Their thermal stability was enhanced and the fluorescence intensity in chloroform was significantly improved (Figure 10a,b). The fluorescence spectra indicated that the Eu/PMMA nanofibers had a maximum luminescence intensity at a content of $12 \mathrm{wt} \%$. When PMMA had a mass fraction of 10-14 wt \%, a carbonyl bond of PMMA was matched with an $\mathrm{Eu}(\mathrm{III})$ ion of complex $\mathbf{1}$ or $\mathbf{2}$. Through a comparison with the fluorescence properties of the complexes 3 and 4 and $\mathrm{Eu}(\mathrm{TFT})_{3}(\mathrm{TPPO}) / \mathrm{PVP}$ and $\mathrm{Eu}(\mathrm{TFT})_{3}(\mathrm{TPPO})_{2} / \mathrm{PVP}$, it was found that the rare earth complexes could form nine coordination bonds, which had a significant effect on the luminescence properties of the complexes. However, the ninth coordination bond was not a very stable coordination bond. The auxiliary ligands and the rare earth complexes of a different molar ratio formed new complexes, but their luminescence properties underwent little change. However, two different auxiliary ligands were involved in coordination, and the optical properties of the complexes could be greatly changed. The auxiliary ligands could be TPPO, phen, bpy, or the polymers with carbonyl groups.

Complexes 5 and 6 were added to chloroform $(50 \mathrm{~mL})$, respectively. Then, PVP was added. The fluorescence intensity of $\mathrm{PVP} /$ complexes 5 and $\mathbf{6}$ were increased by one to three times, but it was far less than the fluorescence intensity of the PVP/complexes 3 and 4 (Figure 11a,b). The increase in the number of fluorine atoms in PFP would have enhanced the aggregation-induced effect of 
the rare earth complexes. From the experimental data, we found that when the concentration of $\mathrm{PVP} /$ complexes was diluted two times, the fluorescence intensity was significantly enhanced, which was due to the attenuation of the aggregation-induction effect. When the solution was diluted four times, the fluorescence intensity decreased due to a decrease in concentration.

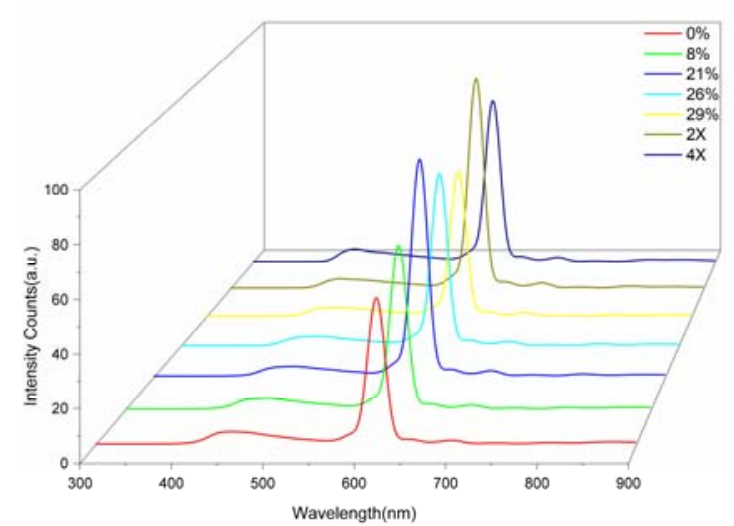

(a)

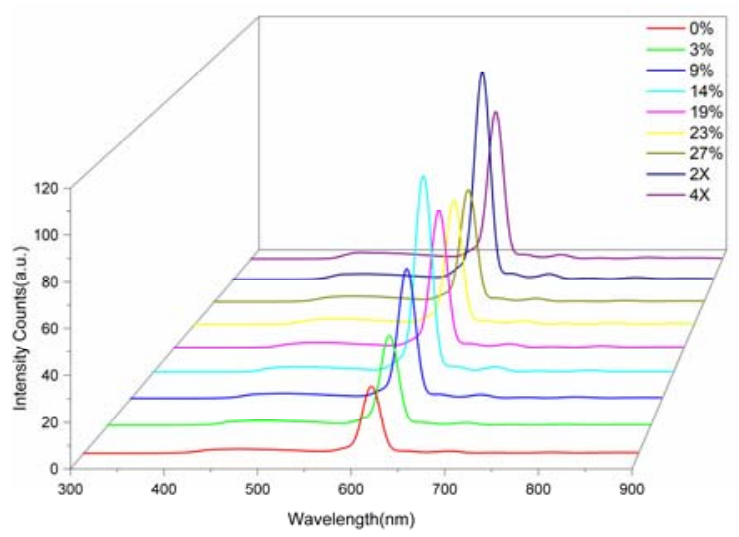

(b)

Figure 11. The liquid fluorescence curve spectrograms of complexes 5 (a) and $\mathbf{6}(\mathbf{b})$ in chloroform.

\subsection{Fluorescence Lifetimes and Fluorescence Quantum Efficiencies of Complexes 1-6 and $\mathrm{Eu}(\mathrm{TFT})_{3}$ bpy/PMMA, Eu(TFT) ${ }_{3}$ phen/PMMA}

When the fluorescence lifetimes of complexes 1-6 and Eu(bpy $)_{3}$ bpy/PMMA, $\mathrm{Eu}$ (phen) $)_{3}$ phen/PMMA were measured, it was found that the excited state molecules emitted fluorescence in the form of radiative transition to the ground state. However, there was also quenching and energy transfer between the molecules. The interaction between the molecules could accelerate the molecules of excited states back to the ground state, so the fluorescence lifetimes were reduced. The fluorescence lifetimes of the polymers were about $10^{-8} \mathrm{~s}$, which was due to the strong aggregation-induced effect between the polymer molecules. The lifetime $\tau$ was related to the rate constant of these processes, and the rate constant $\mathrm{k}$ of the total withdrawal process could be expressed by the sum of the rate constants of various withdrawal processes $\left(k=k_{\mathrm{F}}+\sum k_{\mathrm{i}}\left(k_{\mathrm{F}}\right.\right.$ : decay rate constant of various non-radiation processes); $\left.\tau=1 / k=1 /\left(k_{\mathrm{F}}+\sum k_{\mathrm{i}}\right)\right)$.

When the rare earth complexes and the polymers were mixed, the fluorescence lifetime of the complex was reduced by coordinating with the polymer ligand with a high molecular weight, which consumed excessive energy. The fluorescence decay curves (Figure 12) and emission spectrums (Figure 8) of the rare earth complexes and Eu(TFT) ${ }_{3}$ bpy/PMMA, Eu(TFT) $)_{3}$ phen/PMMA showed that the coordination of PMMA and Eu(III) ions could increase the emission intensity of $\mathrm{Eu}(\mathrm{III})$ ions and increase the interaction between molecules.

The fluorescence quantum efficiencies of $\mathrm{Eu}(\mathrm{TFT})_{3}$ phen/PMMA and $\mathrm{Eu}(\mathrm{TFT})_{3}$ bpy/PMMA were attenuated compared to $\mathrm{Eu}(\mathrm{TFT})_{3}$ phen and $\mathrm{Eu}(\mathrm{TFT})_{3}$ bpy (Table A4). This is the same mechanism as the attenuation of the fluorescence lifetime of $\mathrm{Eu}(\mathrm{TFT})_{3}$ phen/PMMA, which was mainly caused by the aggregation-induced quenching of the rare earth complexes and the polymers. However, by comparing the fluorescence lifetimes and quantum efficiencies of complexes 3-6, the fluorescence lifetimes and quantum efficiencies of the rare earth complexes could be significantly improved with an increase in the number of auxiliary ligands. This is mainly because the two TPPO molecules were better for the sensitization of the rare earth ions. 


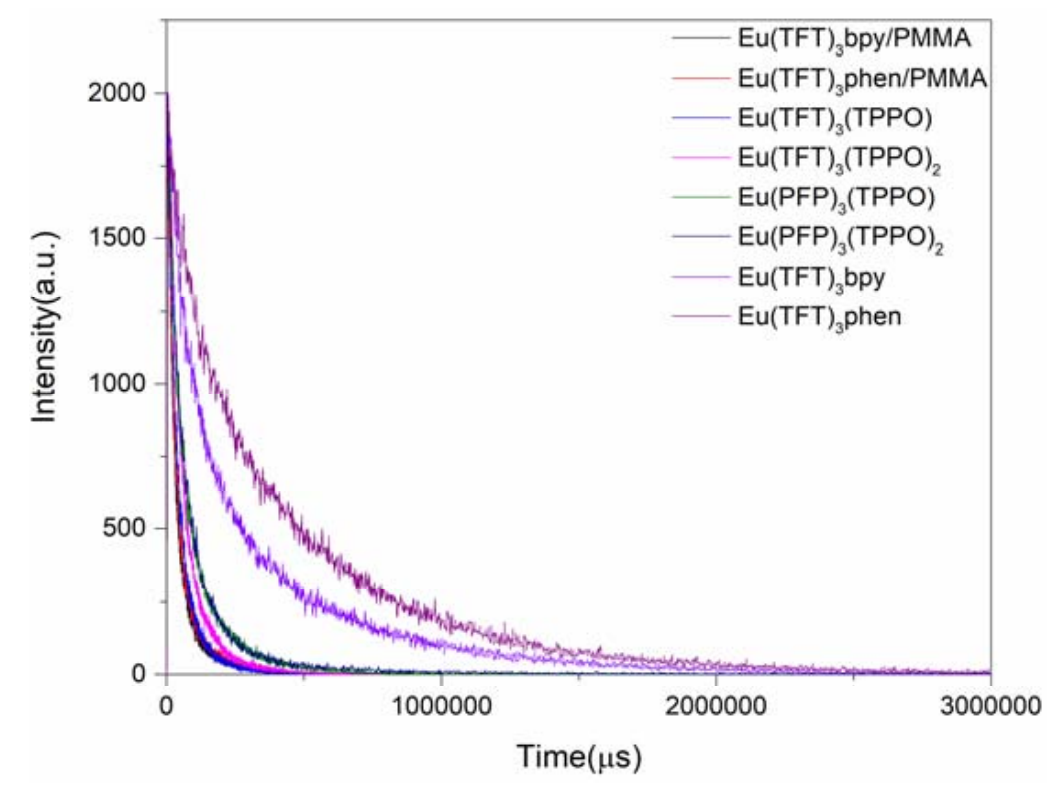

Figure 12. The fluorescence decay curves of complexes 1-6 and Eu(TFT) $)_{3} b p y / P M M A$, $\mathrm{Eu}(\mathrm{TFT})_{3}$ phen/PVP.

\section{Conclusions}

In summary, we reported the preparation of six novel eight-coordinated $\mathrm{Eu}(\mathrm{III})$ complexes. Luminescence studies revealed that TFT, PFP, PMMA, and PVP were effective sensitizers on the luminescence of $\mathrm{Eu}(\mathrm{III})$ ions due to the ligand transferring the absorbed energy effectively to the emitting level of the center metal ion. In addition, the coordination and luminescence mechanism of the rare earth complexes and the polymers were investigated. The experimental data and results showed that the polymers could be used as an auxiliary ligand to change the optical properties of the rare earth complexes. The rare earth complexes could enhance electron transition in polymer molecules. The polymers and the complexes had two strong emission peaks, such that the light color was changed. A fluorine atom could enhance the aggregation-induced effect of PMMA and PVP/complexes.

Supplementary Materials: The following are available online at http:/ / www.mdpi.com/2073-4360/10/5/508/s1, Cif S1: CCDC 1484014-Complex 1, Cif S2: CCDC 1524434-Complex 2.

Author Contributions: Conceptualization, Y.H. and S.W.; Methodology, Y.H.; Software, H.S.; Validation, W.Z., G.Y. and H.S.; Formal Analysis, W.Z.; Investigation, S.W.; Resources, G.Y.; Data Curation, Y.H.; Writing-Original Draft Preparation, W.Z.; Writing-Review \& Editing, Y.H.; Visualization, G.Y.; Supervision, S.W.; Project Administration, Y.H.; Funding Acquisition, Y.H. and S.W.

Acknowledgments: The authors are grateful to National Science Foundation of China (51773053) and Natural Science Foundation of Heilongjang Province of China (B2017010).

Conflicts of Interest: The authors declare no conflict of interest. 


\section{Appendix A}

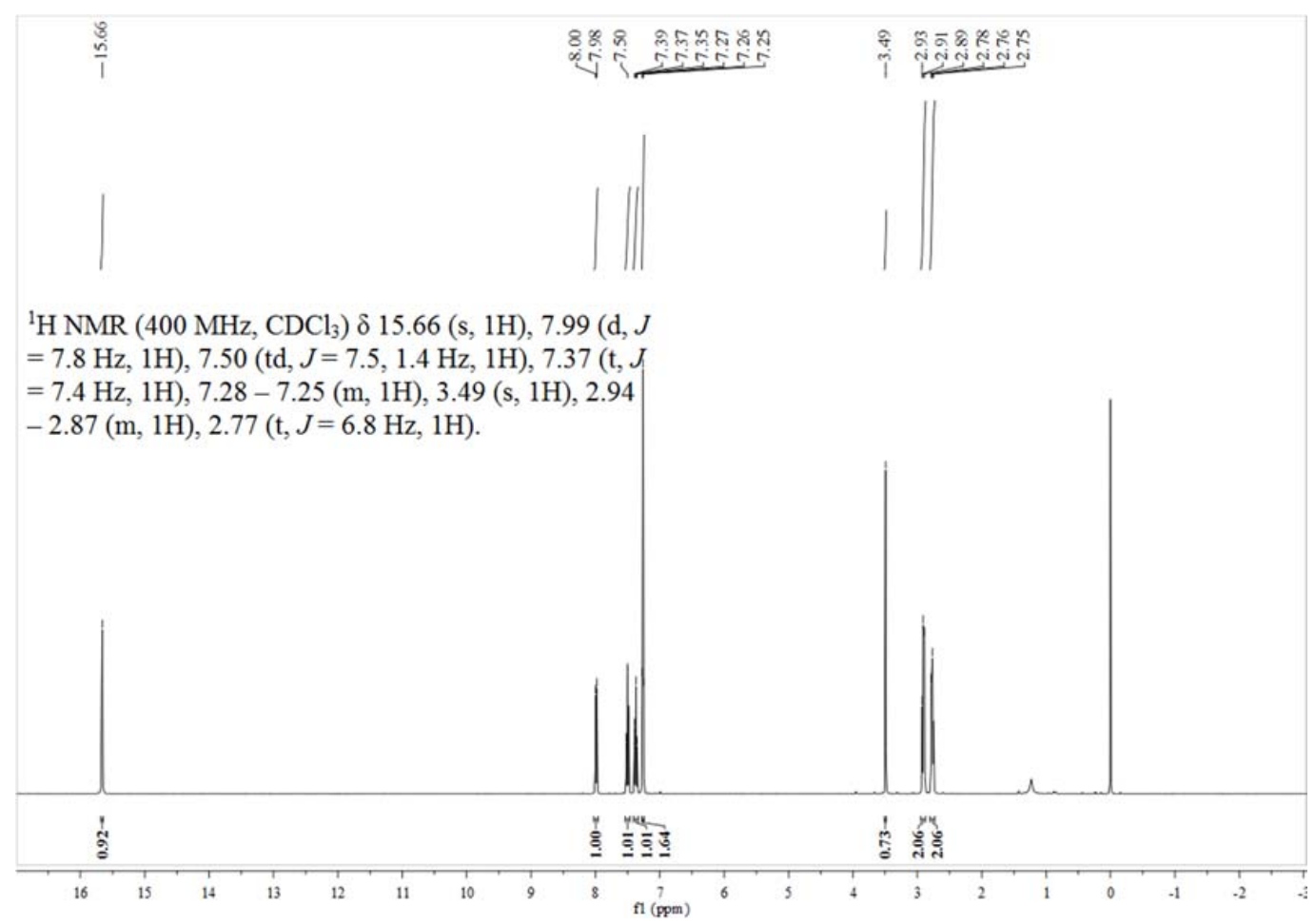

Figure A1. ${ }^{1} \mathrm{H}$ NMR spectra of TFT.

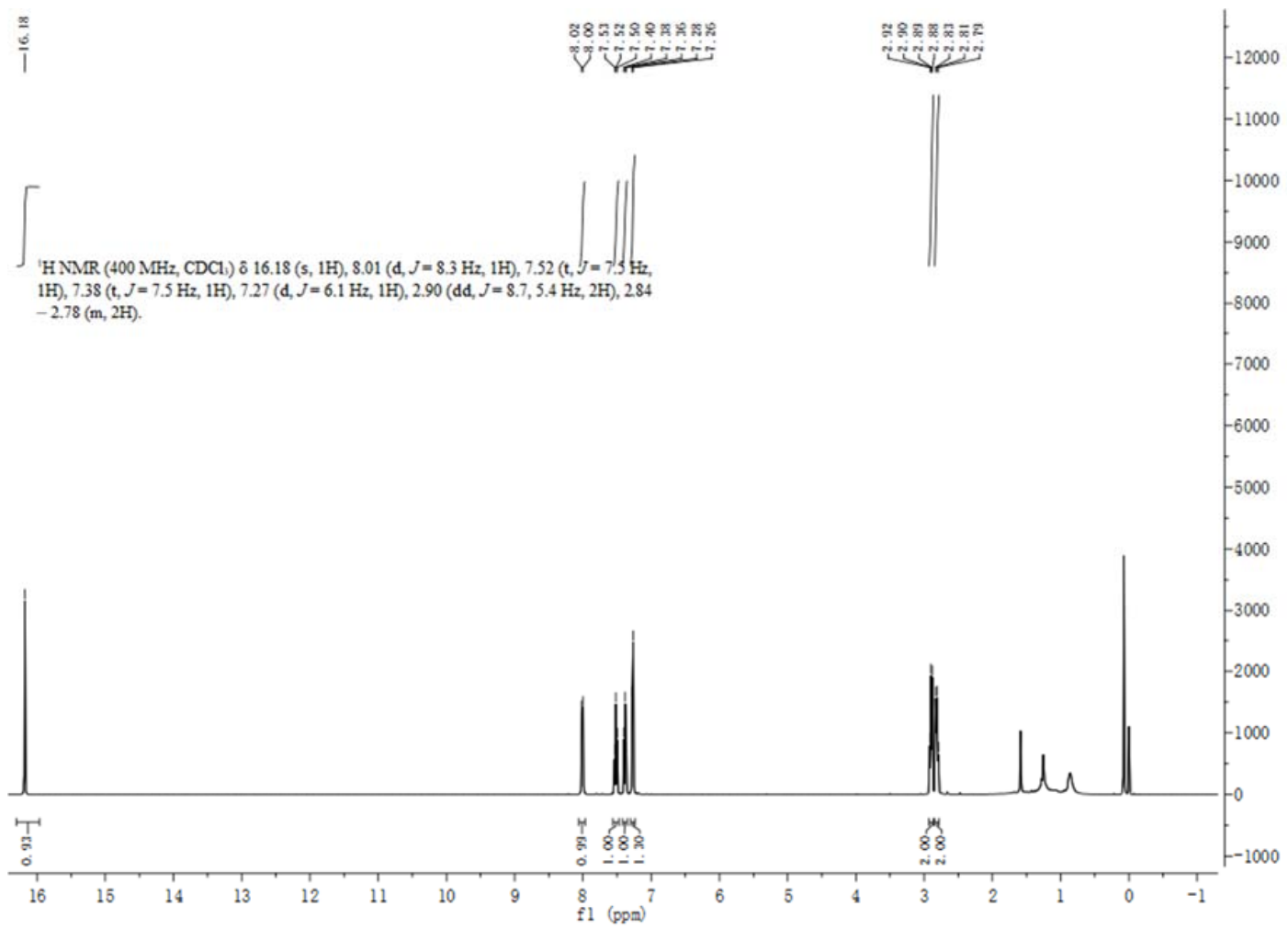

Figure A2. ${ }^{1} \mathrm{H}$ NMR spectra of PFP. 


\section{Appendix B}

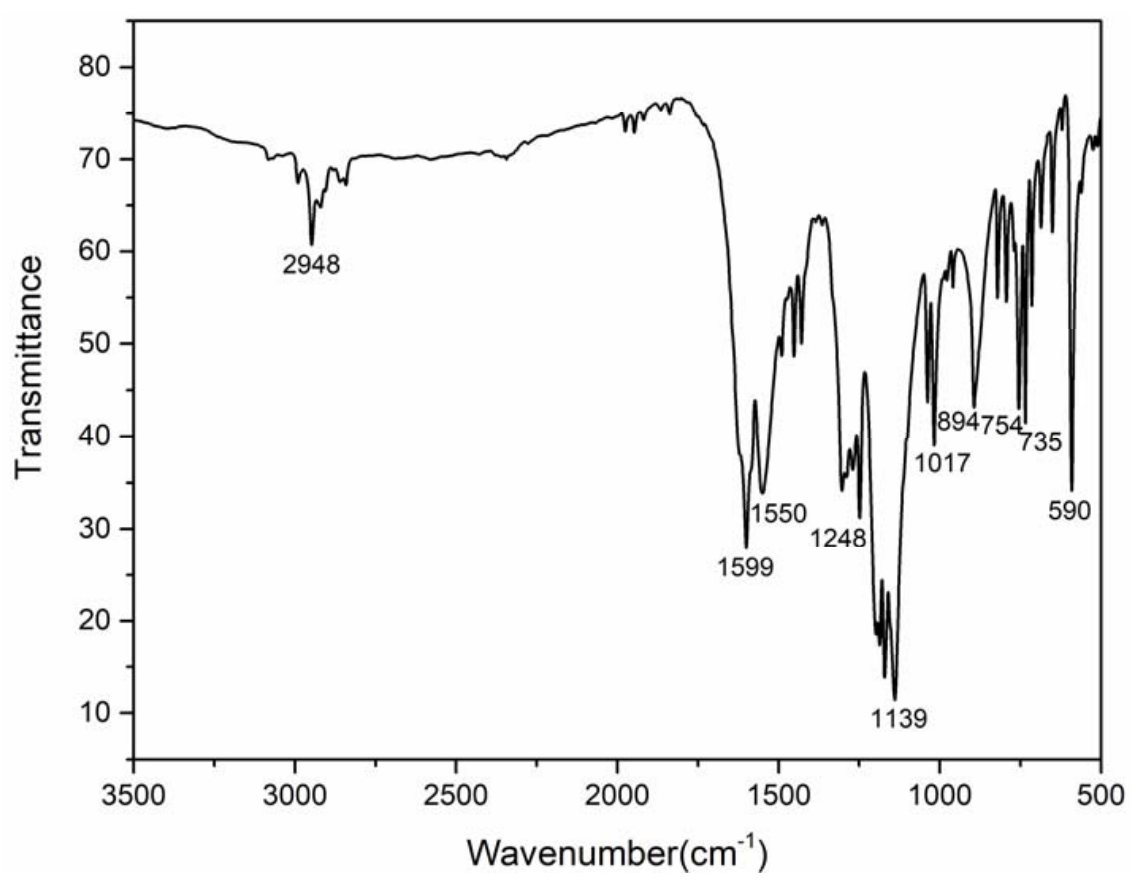

Figure A3. FTIR spectra of TFT.

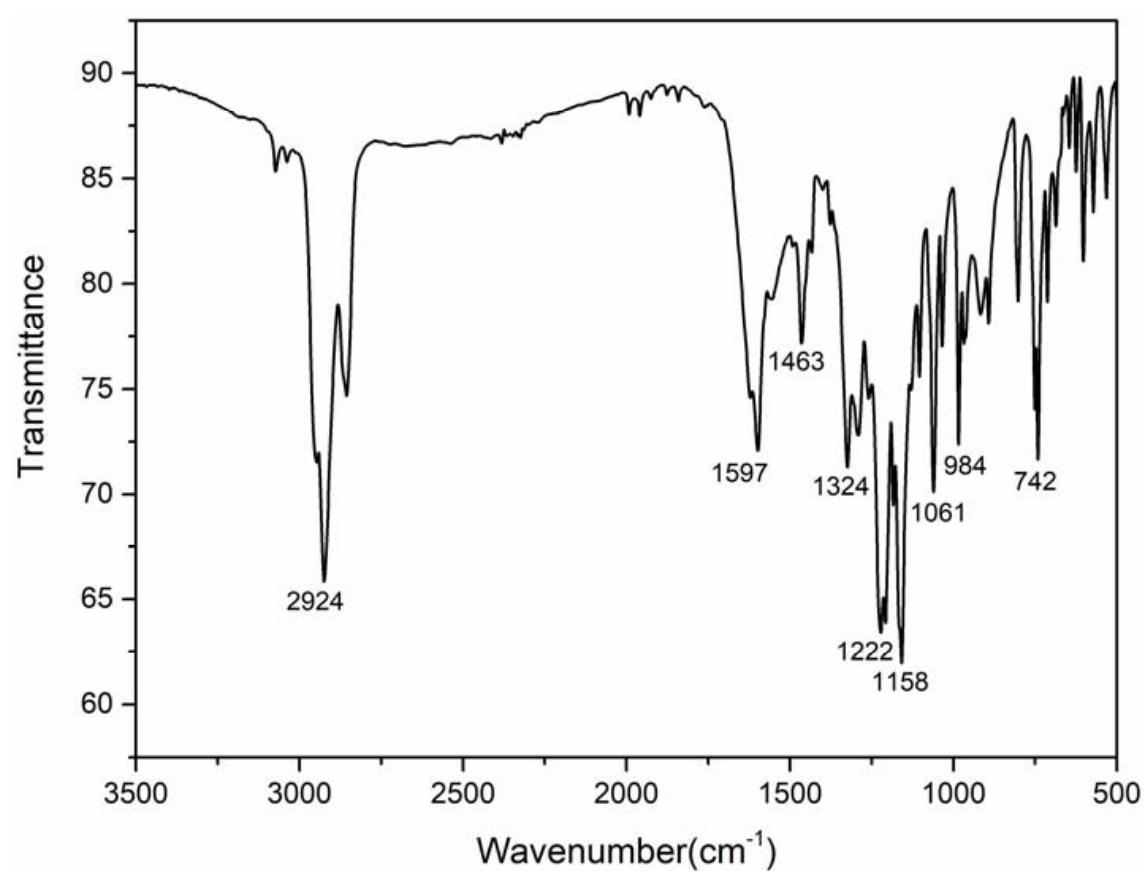

Figure A4. FTIR spectra of PFP. 


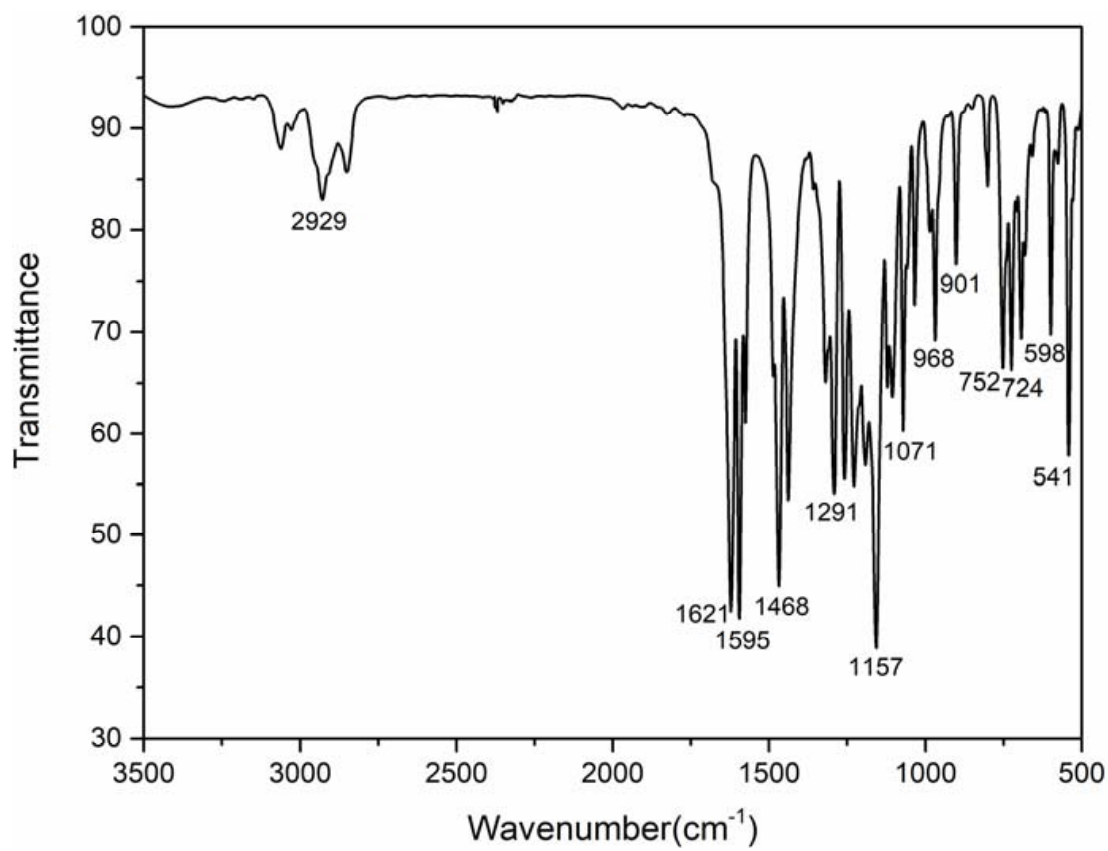

Figure A5. FTIR spectra of $\mathrm{Eu}(\mathrm{PFP})_{3} \mathrm{TPPO}$.

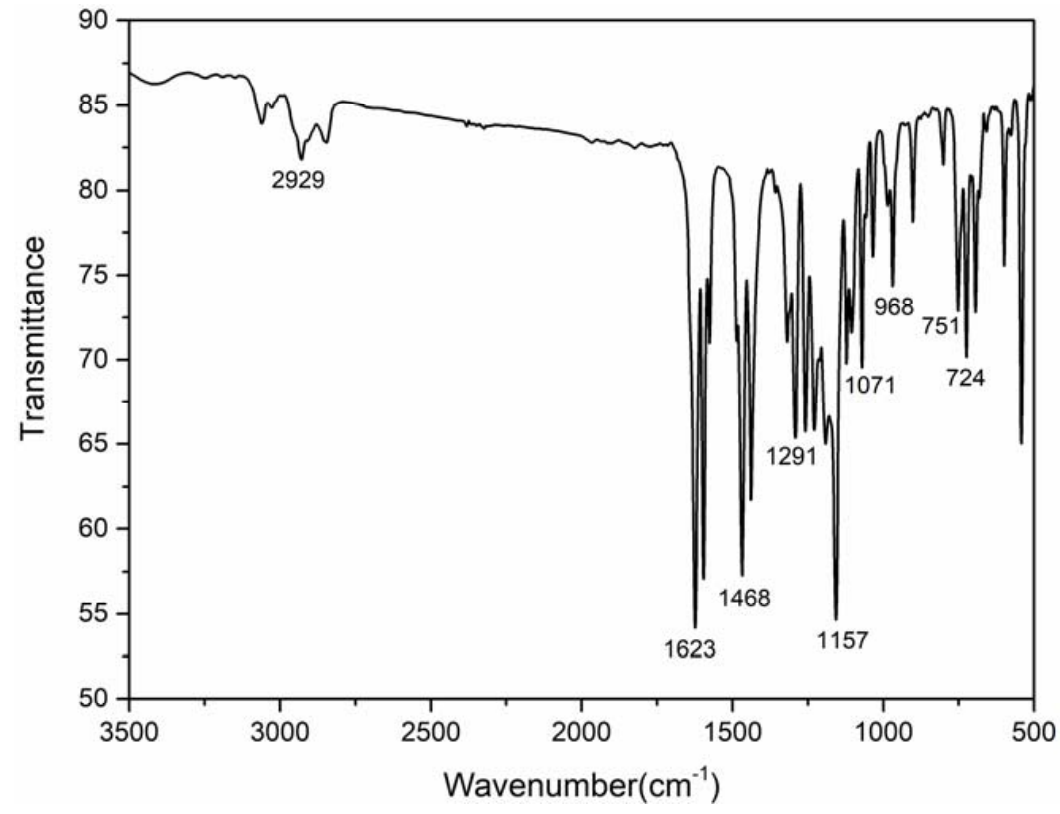

Figure A6. FTIR spectra of $\mathrm{Eu}(\mathrm{PFP})_{3}(\mathrm{TPPO})_{2}$. 


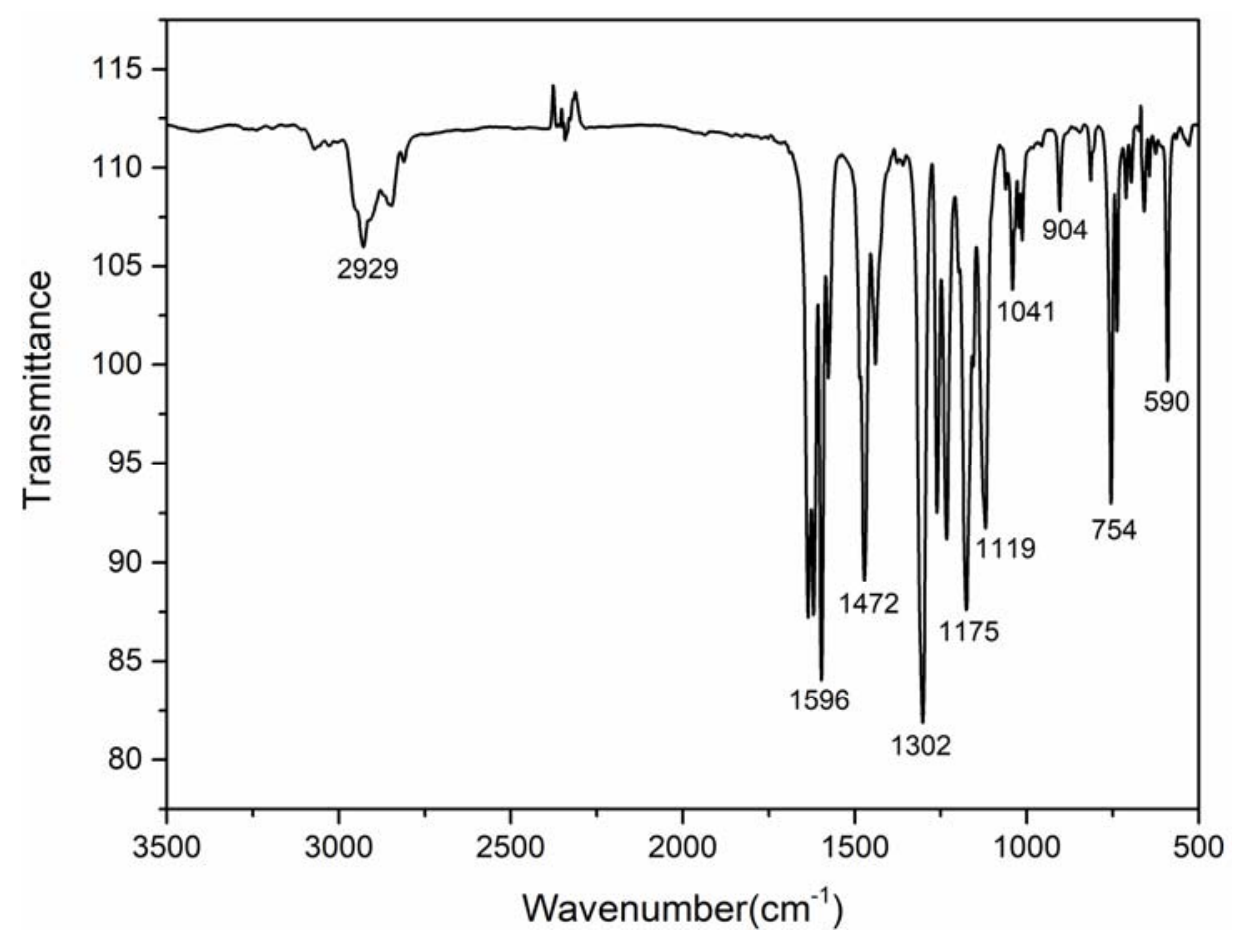

Figure A7. FTIR spectra of $\mathrm{Eu}(\mathrm{TFT})_{3}$ bpy.

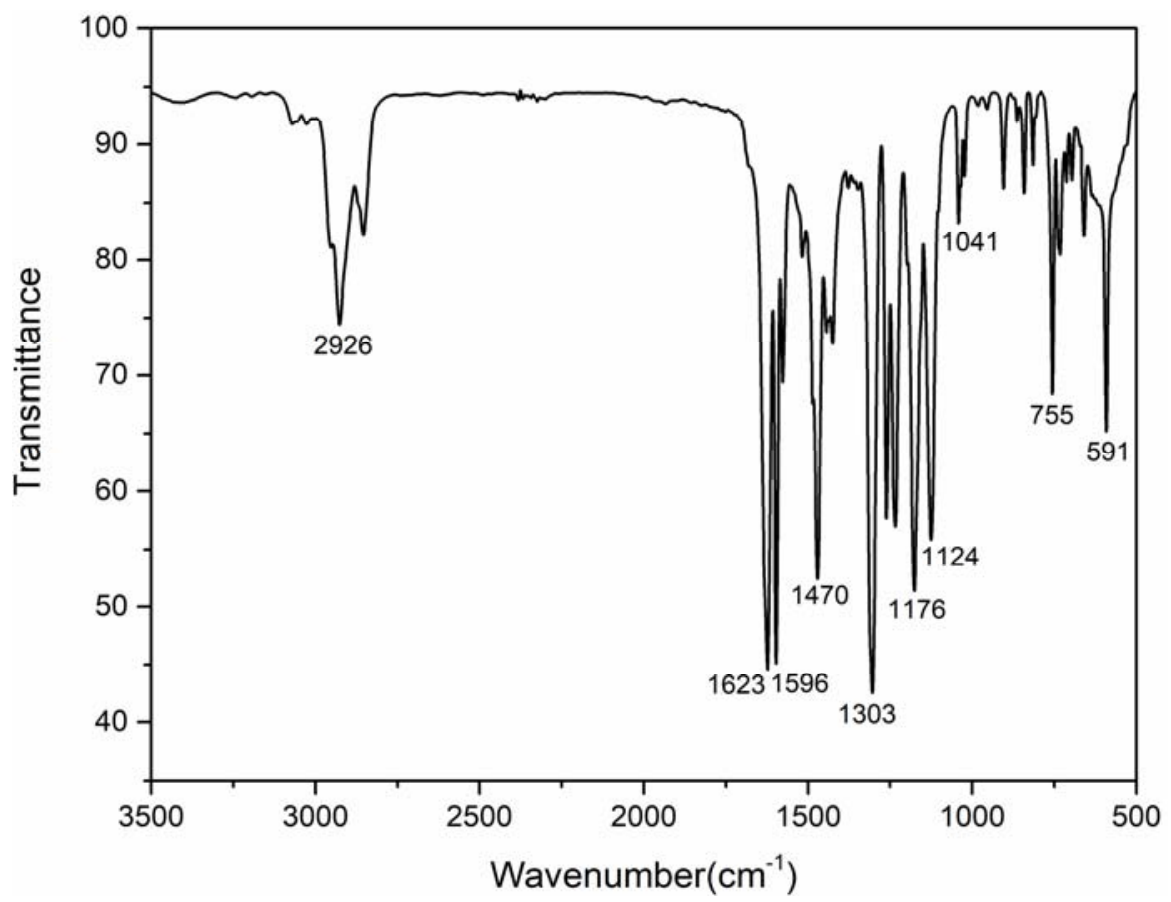

Figure A8. FTIR spectra of $\mathrm{Eu}(\mathrm{TFT})_{3}$ phen. 


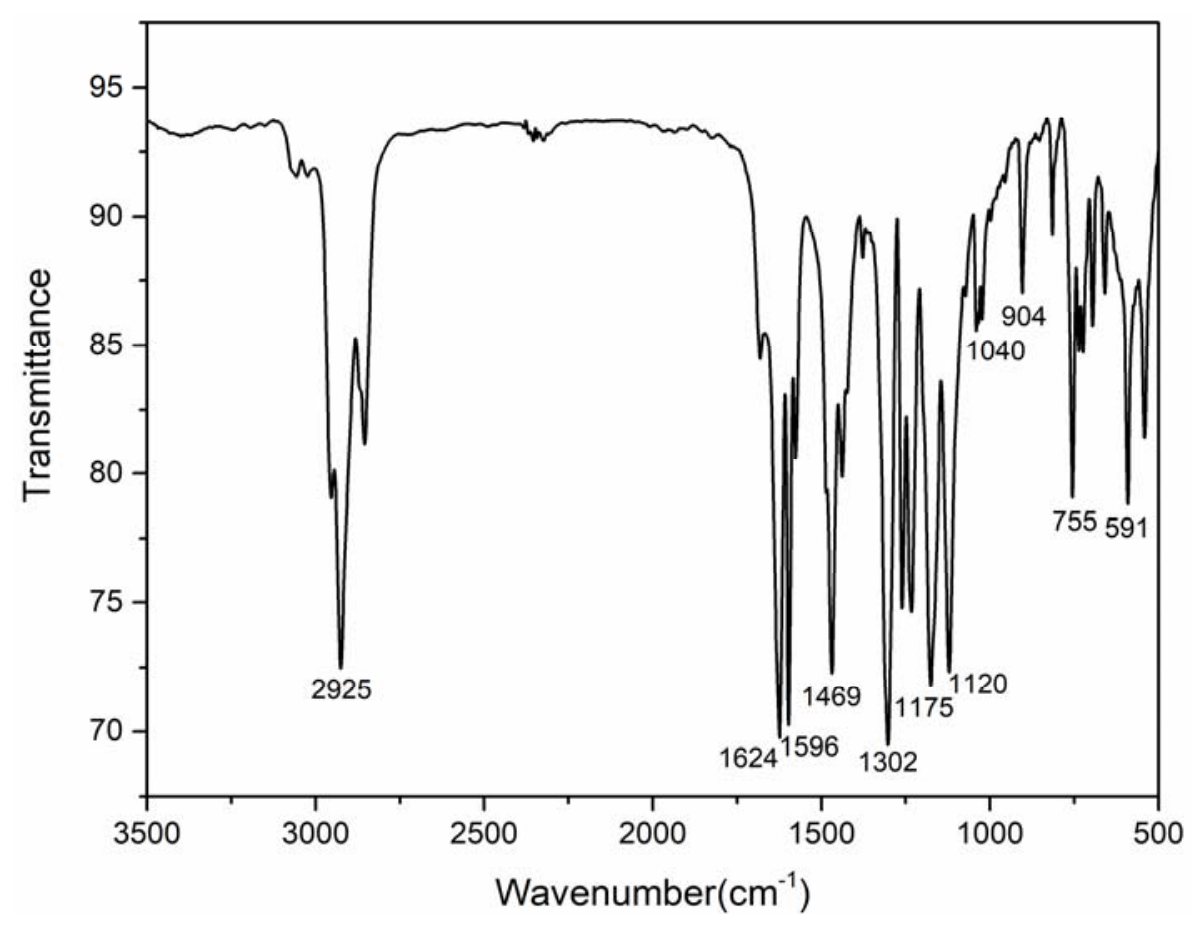

Figure A9. FTIR spectra of $\mathrm{Eu}(\mathrm{TFT})_{3} \mathrm{TPPO}$.

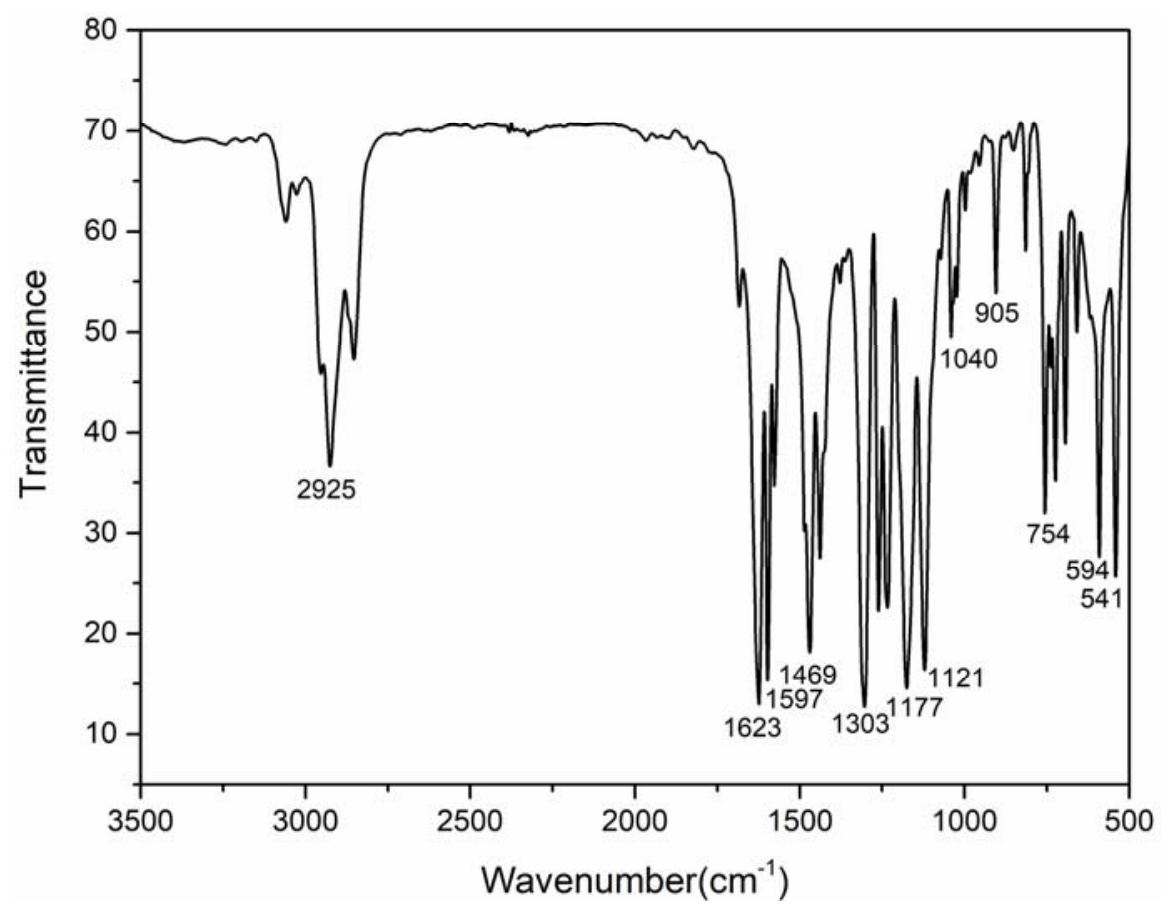

Figure A10. FTIR spectra of $\mathrm{Eu}(\mathrm{TFT})_{3}(\mathrm{TPPO})_{2}$. 


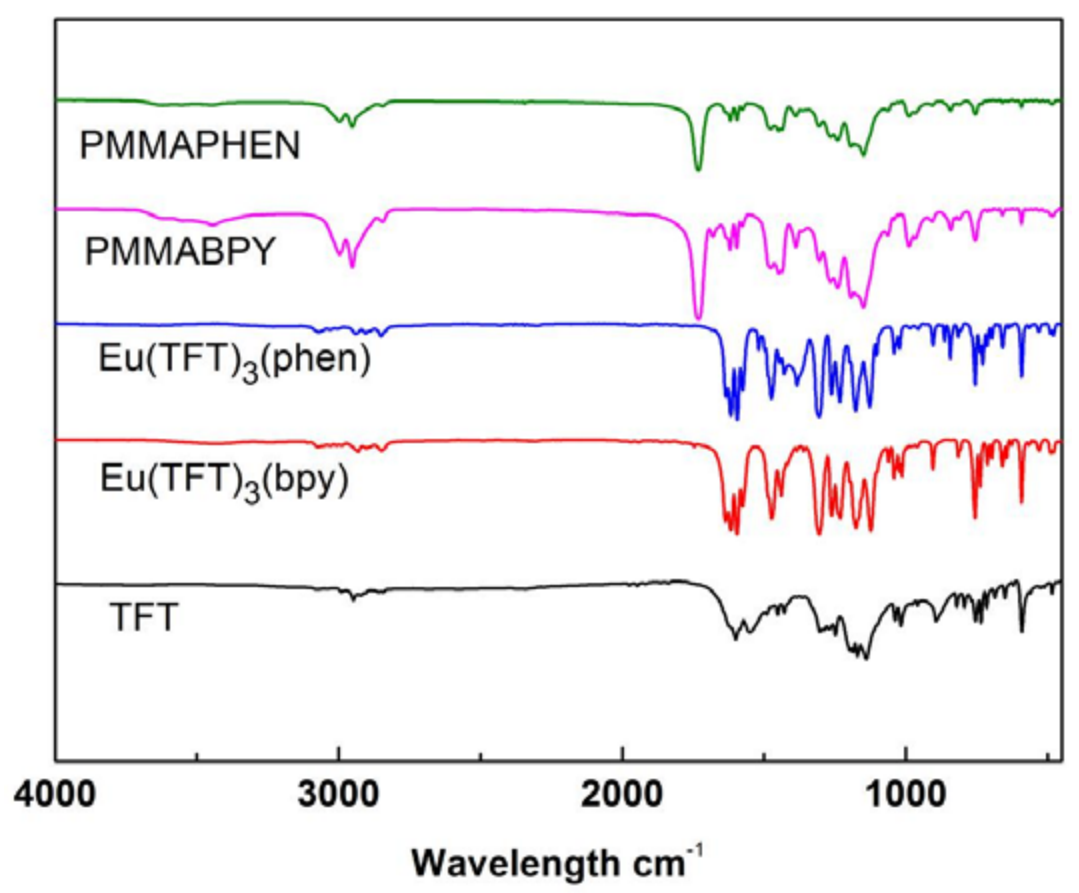

Figure A11. FTIR spectra of TFT, complexes 1 and 2, and Eu/PMMA.

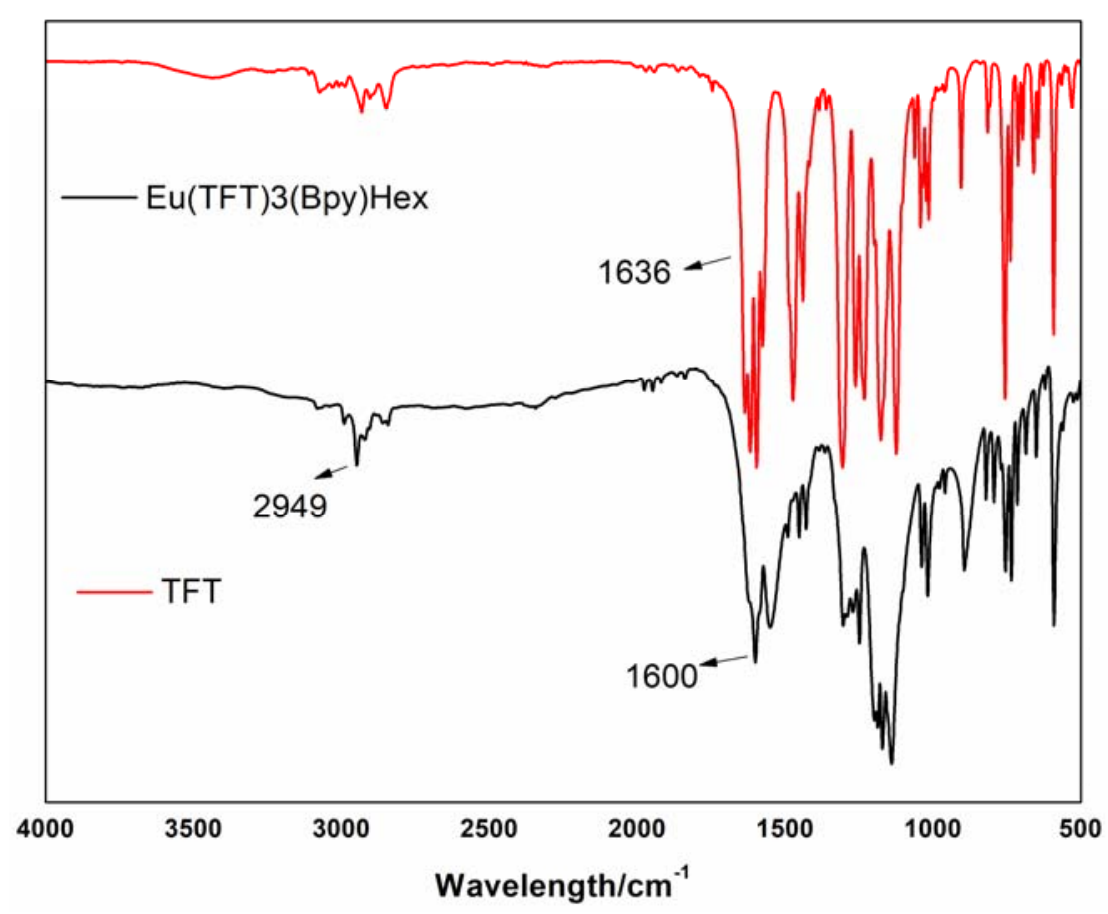

Figure A12. FTIR spectra of TFT and complex 2. 


\section{Appendix C}

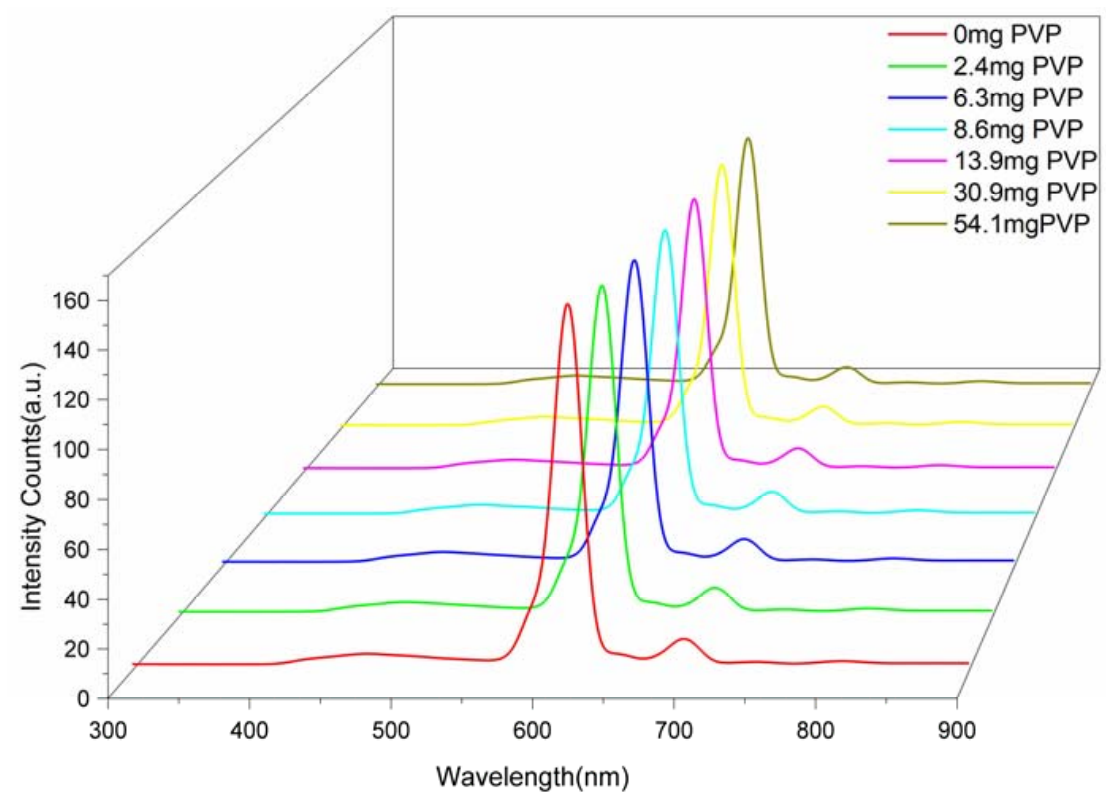

Figure A13. Fluorescence spectrum of PVP/complex 3 in dimethyl formamide (DMF).

\section{Appendix D}

Table A1. Selected bond lengths $(\AA)$ in Eu(TFT) $)_{3}$ (phen).

\begin{tabular}{ll}
\hline \multicolumn{3}{c}{ Bond Lengths } \\
\hline $\mathrm{Eu}(1)-\mathrm{O} 1$ & $2.347(4)$ \\
$\mathrm{Eu}(1)-\mathrm{O} 2$ & $2.351(5)$ \\
$\mathrm{Eu}(1)-\mathrm{O} 3$ & $2.324(4)$ \\
$\mathrm{Eu}(1)-\mathrm{O} 4$ & $2.347(4)$ \\
$\mathrm{Eu}(1)-\mathrm{O} 5$ & $2.354(4)$ \\
$\mathrm{Eu}(1)-\mathrm{O} 6$ & $2.358(4)$ \\
$\mathrm{Eu}(1)-\mathrm{N} 1$ & $2.590(5)$ \\
$\mathrm{Eu}(1)-\mathrm{N} 2$ & $2.586(5)$ \\
\hline
\end{tabular}

Table A2. Selected bond lengths $(\AA)$ in $\operatorname{Eu}(\mathrm{TFT})_{3}(\mathrm{bpy}) \cdot \mathrm{Hex}$.

\begin{tabular}{llcc}
\hline \multicolumn{4}{c}{ Bond Lengths } \\
\hline $\mathrm{Eu}(1)-\mathrm{O} 1$ & $2.341(3)$ & $\mathrm{C}(3 \mathrm{~S})-\mathrm{C}(2 \mathrm{~S})$ & $1.41(3)$ \\
$\mathrm{Eu}(1)-\mathrm{O} 2$ & $2.368(3)$ & $\mathrm{C}(3 \mathrm{~S})-\mathrm{C}(3 \mathrm{~S}) \# 1$ & $1.46(4)$ \\
$\mathrm{Eu}(1)-\mathrm{O} 3$ & $2.356(3)$ & $\mathrm{C}(1 \mathrm{~S})-\mathrm{C}(2 \mathrm{~S})$ & $1.542(9)$ \\
$\mathrm{Eu}(1)-\mathrm{O} 4$ & $2.347(3)$ & & \\
$\mathrm{Eu}(1)-\mathrm{O} 5$ & $2.351(3)$ & & \\
$\mathrm{Eu}(1)-\mathrm{O} 6$ & $2.379(3)$ & & \\
$\mathrm{Eu}(1)-\mathrm{N} 1$ & $2.576(3)$ & & \\
$\mathrm{Eu}(1)-\mathrm{N} 2$ & $2.590(8)$ & & \\
\hline
\end{tabular}


Table A3. Absorptions of Eu complex 1 Calculated with the TDDFT Method.

\begin{tabular}{cccccc}
\hline Sn & Confign & CI codff & E/nm (eV) & Oscillator & Assignt \\
\hline S1 & $\mathrm{H} \rightarrow \mathrm{L}+2$ & 0.2898 & $277.23(4.47)$ & 0.1533 & ILCT/LMCT/MLCT/MC \\
S2 & $\mathrm{H} \rightarrow \mathrm{L}+3$ & 0.3316 & $275.69(4.49)$ & 0.3093 & ILCT \\
S3 & $\mathrm{H}-1 \rightarrow \mathrm{L}+2$ & 0.1572 & $266.16(4.66)$ & 0.4822 & ILCT/LMCT/MLCT/MC \\
S4 & $\mathrm{H} \rightarrow \mathrm{L}+1$ & 0.1091 & $254.70(4.87)$ & 0.0279 & $\mathrm{LMCT} / \mathrm{MLCT} / \mathrm{MC}$ \\
S5 & $\mathrm{H} \rightarrow \mathrm{L}$ & 0.1363 & $249.71(4.97)$ & 0.0024 & $\mathrm{LMCT} / \mathrm{MLCT} / \mathrm{MC}$ \\
\hline
\end{tabular}

Table A4. Luminescence lifetimes and quantum yields of complexes.

\begin{tabular}{lcc}
\hline \multicolumn{1}{c}{ Samples } & $\boldsymbol{\tau}(\mathbf{m s})$ & $\boldsymbol{\phi}_{\text {overall }}(\mathbf{\%})$ \\
\hline Eu(TFT) $)_{3}$ phen & 314 & 52.17 \\
Eu(TFT) $)_{3}$ bpy & 172 & 48.93 \\
Eu(TFT) $)_{3}$ phen/PMMA & 28 & 19.17 \\
Eu(TFT) $)_{3}$ bpy/PMMA & 26 & 18.81 \\
Eu(TFT $)_{3}(\mathrm{TPPO})$ & 45.2 & 20.76 \\
$\mathrm{Eu}(\mathrm{TFT})_{3}(\mathrm{TPPO})_{2}$ & 62.4 & 21.97 \\
$\mathrm{Eu}(\mathrm{PFP})_{3}(\mathrm{TPPO})$ & 62 & 21.91 \\
$\mathrm{Eu}(\mathrm{PFP})_{3}(\mathrm{TPPO})_{2}$ & 70 & 22.17 \\
\hline
\end{tabular}

\section{References}

1. Carlos, L.D.; Ferreira, R.A.; Bermudez, V.Z.; Ribeiro, S.J. Lanthanide-containing light-emitting organic-inorganic hybrids: A bet on the future. Adv. Mater. 2009, 40, 509-534. [CrossRef] [PubMed]

2. Shelton, A.H.; Sazanovich, I.V.; Weinstein, J.A.; Ward, M.D. Controllable three-component luminescence from a 1,8-naphthalimide/Eu(III) complex: White light emission from a single molecule. Chem. Commun. 2012, 48, 2749-2751. [CrossRef] [PubMed]

3. Bruno, S.M.; Ferreira, R.A.S.; Carlos, L.D.; Pillinger, M.; Ribeiro-Claro, P.; Goncalves, I.S. Synthesis, characterisation and luminescence properties of MCM-41 impregnated with an $\mathrm{Eu}^{3+}, \beta$-diketonate complex. Microporous Mesoporous Mater. 2008, 113, 453-462. [CrossRef]

4. Wang, D.; Luo, Z.; Liu, Z.; Wang, D.; Fan, L.; Yin, G. Synthesis and photoluminescent properties of Eu (III) complexes with fluorinated $\beta$-diketone and nitrogen heterocyclic ligands. Dyes Pigment. 2016, 132, 398-404. [CrossRef]

5. Hamblin, J.; Abboyi, N.; Lowe, M.P. A binaphthyl-containing Eu complex and its interaction with human serum albumin: A luminescence study. Chem. Commun. 2005, 5, 657-659. [CrossRef] [PubMed]

6. Lv, Y.; Zhang, J.; Cao, W.; Fu, Y.; han, Z. Luminescence properties of complex $\mathrm{Tb}_{0.25} \mathrm{Eu}_{0.75}(\mathrm{TTA})_{2}(\mathrm{~N}-\mathrm{HPA})$ Phen. J. Alloy. Compd. 2009, 468, 406-409. [CrossRef]

7. Lapaev, D.V.; Nikiforov, V.G.; Safiullin, G.M.; Lobkov, V.S.; Knyazev, A.A.; Krupin, A.S.; Galyametdinov, Y.G. Changes in luminescent properties of vitrified films of terbium(III) $\beta$-diketonate complex upon UV laser irradiation. J. Lumin. 2016, 175, 106-112. [CrossRef]

8. Wang, L.; Wang, W.; Zhang, W.; Kang, E.; Huang, W. Synthesis and Luminescence Properties of Novel Eu-Containing copolymers Consisting of Eu(III)-Acrylate- $\beta$-Diketonate Complex Monomers and Methyl Methacrylate. Chem. Mater. 2000, 12, 2212-2218. [CrossRef]

9. Yang, C.; Liu, S.; Xu, J.; Li, Y.; Shang, M.; Lei, L.; Wang, G.; He, J.; Wang, X.; Lu, M. Efficient red emission from poly(vinyl butyral) films doped with a novel europium complex based terpyridyl as ancillary ligand: Synthesis, structural elucidation by Sparkle/RM1 calculation, and photophysical properties. Polym. Chem. 2016, 7, 1147-1157. [CrossRef]

10. Yang, C.; Xu, J.; Zhang, Y.; Li, Y.; Zheng, J.; Lianga, L.; Lu, M. Efficient monochromatic red-light-emitting PLEDs based on a series of nonconjugated Eu-polymers containing a neutral terpyridyl ligand. J. Mater. Chem. C 2013, 1, 4885-4901. [CrossRef]

11. Yang, C.; Xu, J.; Ma, J.; Zhu, D.; Zhang, Y.; Lianga, L.; Lu, M. An efficient long fluorescence lifetime polymer-based sensor based on europium complex as chromophore for the specific detection of $\mathrm{F}^{-}$, $\mathrm{CH}_{3} \mathrm{COO}^{-}$, and $\mathrm{H}_{2} \mathrm{PO}_{4}^{-}$. Polym. Chem. 2012, 3, 2640-2648. [CrossRef] 
12. Cai, J.; Niu, H.; Wang, C.; Ma, L.; Bai, X.; Wang, W. Tuning the bandgaps of polyazomethines containing triphenylamine by different linkage sites of dialdhyde monomers. Electrochim. Acta 2012, 76, 229-241. [CrossRef]

13. And, J.S.Y.; Swager, T.M. Fluorescent Porous Polymer Films as TNT Chemosensors: Electronic and Structural Effects. J. Am. Chem. Soc. 2017, 120, 11864-11873.

14. Li, W.; Tao, Y.; An, G.; Yan, P.; Li, Y.; Li, G. One-dimensional luminescent composite nanofibers of $\mathrm{Eu}(\mathrm{TFI})_{3} \mathrm{TPPO} / \mathrm{PVP}$ prepared by electrospinning. Dyes Pigment. 2017, 146, 47-53. [CrossRef]

15. Zhang, X.; Wen, S.; Hu, S.; Chen, Q.; Fong, H.; Zhang, L.; Liu, L. Luminescence Properties of Eu(III) Complex/Polyvinylpyrrolidone Electrospun Composite Nanofibers. J. Phys. Chem. C 2013, 114, 3898-3903. [CrossRef]

16. Miller, R.D.; Hofer, D.; Rabolt, J.; Fickes, G.N. Anomalously long-wavelength electronic transition in conformationally locked organosilane high polymers. J. Am. Chem. Soc. 2002, 107, 2172-2174. [CrossRef]

17. Jiang, B.; Yang, S.W.; Bailey, S.L.; Hermans, L.G.; Niver, R.A.; Bolcar, M.A.; Jones, W.E., Jr. Toward transparent molecular wires: Electron and energy transfer in transition metal derivatized conducting polymers. Coord. Chem. Rev. 1998, 171, 365-386. [CrossRef]

18. Taydakov, I.V.; Akkuzina, A.A.; Avetisov, R.I.; Khomyakov, A.V.; Saifutyarov, R.R.; Avetissov, I.C. Effective electroluminescent materials for OLED applications based on lanthanide 1,3-diketonates bearing pyrazole moiety. J. Lumin. 2016, 177, 31-39. [CrossRef]

19. Zhai, L.; Zhang, F.; Sun, J.; Liu, M.; Sun, M.; Lu, R. New non-traditional oranogelator of $\beta$-diketone-boron difluoride complexes with terminal tetraphenylethene: Self-assembling and fluorescent sensory properties towards amines. Dyes Pigment. 2017, 145, 54-62. [CrossRef]

20. Zhang, X.; Lu, R.; Jia, J.; Liu, X.; Xue, P.; Xu, D.; Zhou, H. Organogel based on $\beta$-diketone-boron difluoride without alkyl chain and $\mathrm{H}$-bonding unit directed by optimally balanced $\pi-\pi$ interaction. Chem. Commun. 2010, 46, 8419-8421. [CrossRef] [PubMed]

21. Pereira, C.C.; Dias, S.; Coutinho, I.; Leal, J.P.; Branco, L.C.; Laia, C.A. Europium(III) tetrakis(beta-diketonate) complex as an ionic liquid: A calorimetric and spectroscopic study. Inorg. Chem. 2013, 52, 3755-3764. [CrossRef] [PubMed]

22. Melby, L.R.; Rose, N.J.; Abramson, E.; Caris, J.C. Synthesis and Fluorescence of Some Trivalent Lanthanide Complexes. J. Am. Chem. Soc. 1964, 86, 5117-5125. [CrossRef]

23. Armelao, L.; Quici, S.; Barigelletti, F.; Accorsi, G.; Bottaro, G.; Cavazzini, M.; Tondello, E. Design of luminescent lanthanide complexes: From molecules to highly efficient photo-emitting materials. Coord. Chem. Rev. 2010, 254, 487-505. [CrossRef]

24. Han, Y.; Yan, P.; Sun, J.; An, G.; Yao, X.; Li, Y.; Li, G. Luminescence and white-light emitting luminescent sensor of tetrafluoroterephthalate-lanthanide metal-organic frameworks. Dalton Trans. 2017, 46, 4642-4653. [CrossRef] [PubMed]

25. Wang, D.; Pi, Y.; Liu, H.; Wei, X.; Hu, Y.; Zheng, J. Synthesis and spectroscopic behavior of highly luminescent trinuclear europium complexes with tris- $\beta$-diketone ligand. J. Alloy. Compd. 2014, 613, 13-17. [CrossRef]

26. Congiu, M.; Alamiry, M.; Moudam, O.; Ciorba, S.; Richardson, P.R.; Maron, L.; Jones, A.C.; Richards, B.S.; Robertson, N. Preparation and photophysical studies of [Ln(hfac) $\left.{ }_{3} \mathrm{DPEPO}\right], \mathrm{Ln}=\mathrm{Eu}, \mathrm{Tb}, \mathrm{Yb}, \mathrm{Nd}, \mathrm{Gd}$; interpretation of total photoluminescence quantum yields. Dalton Trans. 2013, 42, 13537-13545. [CrossRef] [PubMed]

27. Divya, V.; Sankar, V.; Raghu, K.G.; Reddy, M.L. A mitochondria-specific visible-light sensitized europium beta-diketonate complex with red emission. Dalton Trans. 2013, 42, 12317-12323. [CrossRef] [PubMed]

28. Xu, H.; Hu, H.C.; Cao, C.S.; Zhao, B. Lanthanide organic framework as a regenerable luminescent probe for $\mathrm{Fe}^{3+}$. Inorg. Chem. 2015, 54, 4585-4587. [CrossRef] [PubMed]

29. Ma, X.; Li, X.; Yue, C.; Jin, L.P. Highly Thermostable One-Dimensional Lanthanide(III) Coordination Polymers Constructed from Benzimidazole-5,6-dicarboxylic Acid and 1,10-Phenanthroline: Synthesis, Structure, and Tunable White-Light Emission. Cryst. Growth Des. 2012, 12, 5227-5232. [CrossRef]

30. Freund, C.; Porzio, W.; Giovanella, U.; Vignali, F.; Pasini, M.; Destri, S. Thiophene based europium $\beta$-diketonate complexes: Effect of the ligand structure on the emission quantum yield. Inorg. Chem. 2011, 50, 5417-5429. [CrossRef] [PubMed]

31. Singh, A.K.; Singh, S.K.; Mishra, H.; Prakash, R.; Rai, S.B. Structural, Thermal, and Fluorescence Properties of Eu (DBM) ${ }_{3}$ Phen $_{x}$ Complex Doped in PMMA. J. Phys. Chem. B 2010, 114, 13042-13051. [CrossRef] [PubMed] 
32. Biju, S.; Freire, R.O.; Eom, Y.K.; Scopelliti, R.; Bünzli, J.C.; Kim, H.K. A Eu ${ }^{\mathrm{III}}$ tetrakis ( $\beta$-diketonate) dimeric complex: Photophysical properties, structural elucidation by sparkle/AM1 calculations, and doping into PMMA films and nanowires. Inorg. Chem. 2014, 53, 8407-8417. [CrossRef] [PubMed]

33. Aromí, G.; Gamez, P.; Reedijk, J. Poly beta-diketones: Prime ligands to generate supramolecular metalloclusters. Coord. Chem. Rev. 2008, 252, 964-989.

34. Hou, Z.; Li, G.; Lian, H.; Lin, J. One-dimensional luminescent materials derived from the electrospinning process: Preparation, characteristics and application. J. Mater Chem. 2012, 22, 5254-5276. [CrossRef] 